\title{
Do sovereign ratings cause instability in cross-border emerging CDS markets?
}

\author{
Laura Ballester ${ }^{\text {a, *, Ana González-Urteaga }}{ }^{\text {b }}$

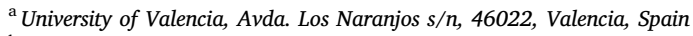 \\ ${ }^{\mathrm{b}}$ INARBE and Public University of Navarre, Arrosadia Campus, 31006, Pamplona, Spain
}

\section{A R T I C L E I N F O}

\section{JEL classification:}

G14

G15

G24

\section{Keywords:}

Sovereign credit risk

Credit ratings

CDS spreads

Emerging markets

Spillover effects

\begin{abstract}
A B S T R A C T
We analyse the cross-border transmission effect of credit ratings on sovereign CDSs covering a broad sample of emerging countries during the period 2004 to 2015. This study differentiates between the spillover and competition effects between and within geographical areas of emerging countries. We find substantial evidence of cross-border effects with asymmetric responses to upgrades and downgrades. The market reaction differs across regions, reflecting how the international and local impact of rating events are due to different types of effects. At the international portfolio level, the competitive effect is dominant over the spillover effect. Negative events in Asia benefit Africa (which is also negatively affected by upgrades in Asia) and Middle East, the latter transmitting in turn to Asia with the same competitive effect. However, some spillover effects are also found both at the portfolio and intra-portfolio levels. The ones associated with downgrades are especially sensitive. In these cases, we identify the particular emerging economies that contribute to an increase in financial instability and to regional spillover effects.
\end{abstract}

\section{Introduction}

In recent decades, rating agencies have come under scrutiny as promoters of financial excesses. The procyclical behavior of sovereign credit rating announcements may have amplified the good and mostly bad times in financial markets. Rating changes may also provide new and private information about a country, intensifying the periods of growth and contraction. As Kaminsky and Schmukler (2002) argue, this effect is particularly significant in emerging economies, where information asymmetry and transparency problems are more profound. ${ }^{1}$ As a result, there is a wide range of literature aiming to assess the impact of sovereign ratings on financial markets, with the main empirical finding supporting the hypothesis that they significantly affect stock, bond and credit swap spread (CDS) markets. However, most of this work studies the impact of rating events in those countries in which the event took place. ${ }^{2}$

Following a new and growing strand of literature, our argument is that the reactions to sovereign rating changes pertaining to one country may have a significant impact on the yields of other countries' sovereign debt and generate cross-border credit transmission.

\footnotetext{
* Corresponding author.

E-mail address: laura.ballester@uv.es (L. Ballester).

${ }^{1}$ Research over the last decade has confirmed this fact by providing strong empirical evidence. See Ismailescu and Kazemi (2010), Christopher et al. (2012), Williams et al. (2015) or Böninghausen and Zabel (2015).

${ }^{2}$ Steiner and Heinke (2001) and Hill et al. (2010), among others, conclude that the reactions of bond spreads to negative announcements are more pronounced than for positive events. Similar results are obtained in the seminar papers of Hull et al. (2004), Norden and Weber (2004), Galil and Soffer (2011) and Finnerty et al. (2013) for alternative international samples of sovereign and corporate CDS spreads.
}

https://doi.org/10.1016/j.iref.2020.12.014

Received 14 April 2019; Received in revised form 20 November 2019; Accepted 12 December 2020

Available online 17 December 2020

1059-0560/@ 2020 Elsevier Inc. All rights reserved. 
This aspect has important implications for investors' portfolio allocation decisions and for policy makers. The global financial crisis of 2008 has increased concerns about the existence of negative spillover effects in response to downgrades that heighten financial instability. This background makes clear that understanding countries' sovereign risk connectedness is key to understanding financial crises and their evolution.

The literature that addresses the cross-border impact of rating changes in the sovereign debt market is mostly concentrated in the bond market (see Gande \& Parsley, 2005 and Ferreira \& Gama, 2007, or Baum et al., 2016, among others). The development of the CDS market since the 2000s has led researchers to focus on this market (see Candelon et al., 2011 or Drago \& Gallo, 2016). The overall result is consistent with more pronounced negative cross-border spillover effects for downgrades; however, there is also evidence with somewhat mixed results. Afonso et al. (2012) show that the spillover effects are mostly not significant for CDS spreads. Ismailescu and Kazemi (2010), which is the only paper so far that analyses the issue for the emerging sovereign CDS market, find stronger spillover impacts for upgrades. We observe that the literature is still too scarce, even more so in the case of the sovereign CDS market for emerging economies, for consistent conclusions to be drawn. In any case, it is important to highlight that previous findings cannot be easily compared since they use quite different samples, in terms of countries, sample periods (generally short and mostly focused on crises) and methodological approaches.

Given this weak background, and noting the lack of evidence about the cross-border impact in the case of the sovereign CDS market for emerging economies, the main contribution of this paper is to fill (at least partially) this gap. Furthermore, as a novel contribution, we carry out different cross-border analyses that enable us to identify particular countries or regions that play important roles in generating credit transmission effects. Accordingly, the main objective of this paper is to shed some light on the literature that addresses the reaction of non-event economies' sovereign CDS markets to a rating event in a given emerging economy. We contribute to such an understanding with a detailed study of the cross-market impact of sovereign rating announcements. To this end, we collect an extensive dataset that comprises the sovereign CDS and rating events for up to 45 emerging countries, covering a broad period from 2004 to 2015. The use of an extensive sample period that covers both crisis and non-crisis periods allows us to investigate differential cross-border effects between positive and negative rating events. We focus not only on assessing whether there is reason to believe that policymakers' concerns about negative spillover effects due to downgrades are not unfounded, but, at the same time, we also analyse whether and the extent to which other countries benefit or suffer from deteriorations or improvements in the credit quality of other countries. We argue that even though negative spillovers are likely to be found in the wake of sovereign downgrades during crisis periods, it is not clear that a similar spillover effect would occur during tranquil times.

In this context, we analyse two different types of cross-border effects. Following the related literature, we use the term "spillover effect" when the effect on other countries or regions is the same as on the event country. In other words, we will detect a spillover effect when a positive (negative) event leads a positive (negative) effect in a non-event country, which signifies an improvement (worsening) in their sovereign credit risk. This spillover effect has also been referred to in the literature as a common effect (Abad et al., 2018; Drago \& Gallo, 2016; Jorion \& Zhang, 2010). Although most studies have focused on analysing this type of effect (see, for instance, Ismailescu \& Kazemi, 2010 or Afonso et al., 2012), in this paper, we complement the research by analysing the cross-border effects that occur in the opposite direction. In fact, if we see emerging countries as competitors, negative (positive) announcements of rating changes can be expected to positively (negatively) affect the refinancing conditions of neighbouring economies. This argument highlights the importance of studying the role of sovereign ratings as forerunners of instability in emerging CDS markets. We refer to this cross-border effect as the "competitive effect", also referred to in the literature as the "differential effect".

Specifically, we find that downgrades in Asia benefit Africa (which is also negatively affected by upgrades in Asia) and Middle East, the latter transmitting in turn to Asia with the same competitive effect. Regarding spillover effects, Eastern Europe reacts positively to upgrades in Asia, whereas the African zone suffers in terms of credit risk from downgrades in Middle East. Finally, it should be noted how America is isolated from other emerging economies by not exhibiting any transmission or receiving effects. The analysis of the countries belonging to the same geographical area reveals a greater variety of transmission effects, depending on the zone considered. To cite an example, most of the intra-portfolio effects associated with upgrades predominate (either positive or negative) in Asia and America. The opposite happens in the rest of the portfolios, such as Eastern Europe, where cross-border effects due to downgrades are predominant, and there are even regions in which only downgrades exhibit a significant intra-regional impact (this is the case for Africa and Middle East). These results highlight that the effect of sovereign ratings on cross-border credit risk cannot be generalised, since it depends on whether the analysis is carried out at the international level (between geographical areas) or at a more local level (between countries in the same region). Although the negative spillovers associated with downgrades are not the only effect we find, they cannot be underestimated. Our empirical evidence identifies those regions and countries that lead these disturbing effects. Policymakers should closely monitor these economies as potential sources of financial instability.

The paper proceeds as follows. Section 2 reviews the existing literature. Section 3 describes the data employed in the analysis, while Sections 4 and 5 contain the hypotheses and the estimation method used to capture the cross-border effects. Section 6 discusses the findings related to the identified effects. Section 7 develops different robustness tests. Finally, Section 8 presents our conclusions.

\section{Literature review}

An increasing body of recent literature notes the need to analyse the existence of cross-border spillover effects, with the aim of determining to what extent non-event countries' sovereign debt is affected by a rating change event in a given country. In this line, using international sovereign bond spreads, Kaminsky and Schmukler (2002), Gande and Parsley (2005), Ferreira and Gama (2007) and Böninghausen and Zabel (2015) all find that downgrades negatively spillover onto other countries' bonds, while the effects of the upgrades are much more limited, if at all. Moreover, the findings support the notion that the impact of the negative spillover is greater 
for countries within the same region, and also during crises. Focusing exclusively on emerging sovereign bond markets, Christopher et al. (2012) also obtain a negative effect associated with downgrades.

More recently, and given the severe Eurozone debt crisis, some papers have focused on analysing the impact of sovereign rating announcements on the European sovereign bond and CDS market. Candelon et al. (2011), De Santis (2012), Baum et al. (2016) and Drago and Gallo (2016) find significant and negative cross-border spillovers for downgrades, which agrees with the previous evidence and also implies that rating agencies announcements could spark financial instability in the sovereign debt markets. However, Afonso et al. (2012) show that the spillover effects are mostly not significant for CDSs. At this point, it is important to note that their sample finishes in 2010, and thus they do not analyse the most critical 2011-2012 period of the Eurozone debt crisis. These somewhat mixed results reinforce our argument that although the spillover effect due to downgrades may be typical of periods of intense crisis, other types of effects cannot be ruled out in periods of greater financial stability.

In this line, Ismailescu and Kazemi (2010) find even stronger impacts for upgrades. More specifically, they observe a positive cross-border spillover due to upgrades, given that the CDS levels of non-event countries decrease. According to these authors, there are several reasons that can explain their different results compared to the previous evidence for bonds. CDS markets are generally more efficient, and are characterized by greater information asymmetry and higher liquidity than bond markets. ${ }^{3}$ They also conclude that the degree of the spillover effects depends on variables such as credit quality, ${ }^{4}$ common creditors or the level of competence of the countries involved. To date, this is the only paper that analyses exclusively the sovereign CDS market for emerging countries. ${ }^{5}$

The latest results support our argument that if we see countries as competitors, one would expect to observe a competitive effect both in the case of downgrades and upgrades, so that such negative (positive) changes in credit quality benefit (harm) competitors by decreasing (increasing) their sovereign credit risk. This statement is in line with the evidence reported by Wengner et al. (2015). Using a sample of international corporate CDS spreads, they document that non-event firms benefit from credit downgrades and suffer from credit upgrades, which is consistent with a competitive effect for both positive and negative events. Chang et al. (2015) focus exclusively on US corporate CDS market with opposite results. They conclude that the intra-industry rivals experience significant credit spread increases during rating downgrades, in accordance with a negative spillover effect. These contradictory results show again the important differences that may exist between regions.

This paper complements the earlier literature by providing new, and to date untested, analyses of the impact of rating events and transmission effects on emerging economies. To the best of our knowledge, this is the first empirical study to investigate cross-border connection among emerging economies using a comprehensive dataset with sovereign CDS spreads for 45 countries. Our sample is therefore larger than those used in previous studies ${ }^{6}$ and the sample period covers a relatively long time period (2004-2015), which enables us to investigate cross-border effects during both crisis and non-crisis periods. By proposing to borrow the idea of firm/industry competitors to emerging countries using sovereign CDS spreads, we also contribute to the literature by testing a great variety of different transmission analyses that have not been investigated until now. Furthermore, we contribute a new international and regional perspective to the literature on the emerging CDS market impact of sovereign ratings by identifying particular countries or regions playing important roles in generating credit transmission.

\section{Data and preliminary descriptive analysis}

The data set comprises sovereign CDS spreads and Standard \& Poor's credit rating events for 45 emerging countries during the period January 1, 2004 to March 4, 2015. Our selection of countries is limited by the availability of data, either CDS or ratings. ${ }^{7}$ Following the related literature, we use the CMA database from Datastream and collect 5-year maturity CDSs on senior debt denominated in US dollars. These are the most liquid contracts and the largest in the CDS market of emerging economies (Jorion \& Zhang, 2007, Ismailescu \& Kazemi, 2010 and Eichengreen et al., 2012, among many others). After analysing the six most used CDS databases in the literature, Mayordomo et al. (2014) indicate that CMA is the leading source of CDS data. The almost 12 years of daily data produces 2915 observations, a broad period to cover both crisis and calm periods. Regarding rating events, many authors such as Gande and Parsley (2005) or Reisen and Von Maltzan (1999) show the advantages of S\&P compared to other rating agencies. According to them, S\&P's rating changes are more frequent, more difficult to predict by the markets and precede those of other rating agencies.

Sovereign emerging economies deserve our attention for two main reasons. The first is that since they are normally assessed by the various rating agencies as being non-investment grade, their probability of default is considered to be higher. Nevertheless, sovereign countries do not default in the usual sense of the word. The second reason is that, as Kaminsky and Schmukler (2002) argue, one should

\footnotetext{
${ }^{3}$ Reference papers that show the advantages of CDS spreads over bond spreads are Longstaff et al. (2003), Blanco et al. (2005) and Zhu (2006).

${ }^{4}$ For the stock market, authors like Jorion and Zhang (2010) and Abad et al. (2018) also relate the cross-border effects of the ratings with the level of credit quality of the companies involved.

${ }^{5}$ Ballester and González-Urteaga (2017) focus exclusively on the Latin American CDS market but from another perspective, analysing to what extent the existing cross-border connectedness is influenced by rating events. They find different effects depending on the country and whether the analysis is carried out before or after the event occurs; however, the empirical evidence rejects the existence of negative spillovers due to downgrades.

${ }^{6}$ For example, Ismailescu and Kazemi (2010) have a sample of 22 emerging sovereign CDSs, Christopher et al. (2012) of 15 emerging sovereign bonds and Afonso et al. (2012) of 24 European Union countries.

${ }^{7}$ Even so, our sample is significantly larger than those used in previous studies. We select the 22 emerging countries used by Ismailescu and Kazemi (2010) and expand the sample following the FTSE Russel's 2014 classification, retaining all the emerging countries with the data available in our sample period.
} 
expect to observe a greater cross-border impact of rating changes in emerging markets, in which the lack of transparency and the presence of asymmetric information are more evident.

We have grouped the 45 emerging economies into five portfolios based on their geographical location, selected as follows: Eastern Europe (portfolio made up of 10 countries), Asia (11 countries), Middle East (6 countries), America (13 countries), and Africa (5 countries). In Table 1 we present the descriptive statistics for the daily sovereign CDS spreads for the five representative portfolios and for each of the emerging markets contained therein. Fig. 1 represents, in Panel A, the daily time evolution of two benchmark CDS indexes built based on each country's rating grade category, calculated as the average CDS spreads for all countries within the same investment or speculative grade, while Panel B shows the daily time evolution of the five portfolios. As expected, the speculative CDS index has higher values of credit risk compared to the investment CDS index. While the former includes those emerging economies with credit

Table 1

Descriptive statistics of daily CDS spreads for all the countries and portfolios.

\begin{tabular}{|c|c|c|c|c|c|}
\hline Portfolio/Country & Obs. & Min. & Max. & Mean & Std. Dev. \\
\hline Eastern Europe & 2915 & 14.30 & 563.77 & 135.46 & 105.99 \\
\hline Bulgaria & 2915 & 13.00 & 698.16 & 164.10 & 131.15 \\
\hline Czech Republic & 2912 & 4.30 & 350.00 & 60.20 & 54.39 \\
\hline Estonia & 2366 & 1.00 & 736.80 & 121.01 & 134.30 \\
\hline Hungary & 2915 & 9.20 & 729.89 & 204.43 & 170.68 \\
\hline Lithuania & 2543 & 1.00 & 849.90 & 178.07 & 160.13 \\
\hline Poland & 2915 & 6.80 & 417.58 & 91.32 & 79.61 \\
\hline Romania & 2915 & 17.20 & 780.78 & 199.93 & 149.30 \\
\hline Russia & 2797 & 37.00 & 1116.70 & 185.64 & 147.98 \\
\hline Slovakia & 2912 & 4.00 & 306.01 & 71.83 & 71.36 \\
\hline Slovenia & 2915 & 3.80 & 488.58 & 114.33 & 123.97 \\
\hline Asia & 2915 & 31.50 & 1285.65 & 218.40 & 149.75 \\
\hline China & 2915 & 9.00 & 296.70 & 68.18 & 45.24 \\
\hline India & 2539 & 31.00 & 218.50 & 73.79 & 28.47 \\
\hline Indonesia & 2717 & 91.40 & 1256.70 & 215.04 & 125.76 \\
\hline Kazakhstan & 2490 & 33.30 & 1646.32 & 220.61 & 206.99 \\
\hline Pakistan & 2712 & 146.20 & 5105.70 & 782.05 & 624.49 \\
\hline Philippines & 2901 & 79.47 & 870.00 & 213.15 & 127.16 \\
\hline Malaysia & 2915 & 12.00 & 520.20 & 82.32 & 56.15 \\
\hline Thailand & 2915 & 24.00 & 524.20 & 96.45 & 58.10 \\
\hline South Korea & 2913 & 14.00 & 700.00 & 86.79 & 77.14 \\
\hline Sri Lanka & 1728 & 282.81 & 3000.00 & 578.90 & 492.47 \\
\hline Vietnam & 2624 & 51.90 & 982.90 & 235.83 & 112.38 \\
\hline Middle East & 2915 & 74.19 & 496.74 & 181.74 & 63.62 \\
\hline Bahrain & 1745 & 96.20 & 714.50 & 253.46 & 99.31 \\
\hline Israel & 2822 & 15.00 & 285.41 & 95.37 & 56.71 \\
\hline Lebanon & 2915 & 166.27 & 955.50 & 385.75 & 91.37 \\
\hline Qatar & 2885 & 7.80 & 379.60 & 75.09 & 55.80 \\
\hline Turkey & 1671 & 109.82 & 835.01 & 212.69 & 86.47 \\
\hline Saudi Arabia & 1741 & 43.30 & 335.00 & 96.24 & 49.45 \\
\hline America & 2915 & 78.74 & 919.55 & 307.50 & 159.60 \\
\hline Argentina & 2758 & 1.50 & 4961.65 & 1035.10 & 1025.47 \\
\hline Brazil & 2915 & 61.10 & 900.20 & 199.59 & 138.38 \\
\hline Chile & 2915 & 4.50 & 315.00 & 69.33 & 49.04 \\
\hline Colombia & 2915 & 64.70 & 655.90 & 185.00 & 113.83 \\
\hline Costa Rica & 1867 & 115.00 & 381.10 & 228.32 & 71.44 \\
\hline Dominican Republic & 1322 & 0.00 & 475.52 & 375.16 & 53.08 \\
\hline El Salvador & 2380 & 24.33 & 548.78 & 305.21 & 156.69 \\
\hline Guatemala & 1868 & 122.96 & 304.77 & 209.92 & 37.68 \\
\hline Mexico & 2915 & 28.70 & 606.70 & 115.95 & 68.71 \\
\hline Panama & 2915 & 61.90 & 613.80 & 152.04 & 78.61 \\
\hline Peru & 2835 & 59.90 & 611.20 & 160.71 & 89.00 \\
\hline Uruguay & 1782 & 120.82 & 264.00 & 165.64 & 27.97 \\
\hline Venezuela & 2823 & 118.67 & 8588.31 & 938.62 & 933.81 \\
\hline Africa & 2915 & 36.10 & 551.68 & 195.13 & 124.15 \\
\hline Egypt & 2181 & 68.50 & 843.54 & 356.76 & 196.92 \\
\hline Ghana & 1229 & 28.67 & 656.17 & 373.83 & 170.60 \\
\hline Morocco & 1884 & 70.00 & 500.00 & 190.42 & 59.26 \\
\hline South Africa & 2915 & 23.80 & 683.30 & 142.54 & 85.60 \\
\hline Tunisia & 2915 & 17.96 & 455.10 & 173.36 & 118.46 \\
\hline
\end{tabular}

This table presents the descriptive statistics for the sovereign CDS spreads for all the 45 emerging countries and five portfolios, expressed in basis points. The sample period is from January 1, 2004 to March 4, 2015. 

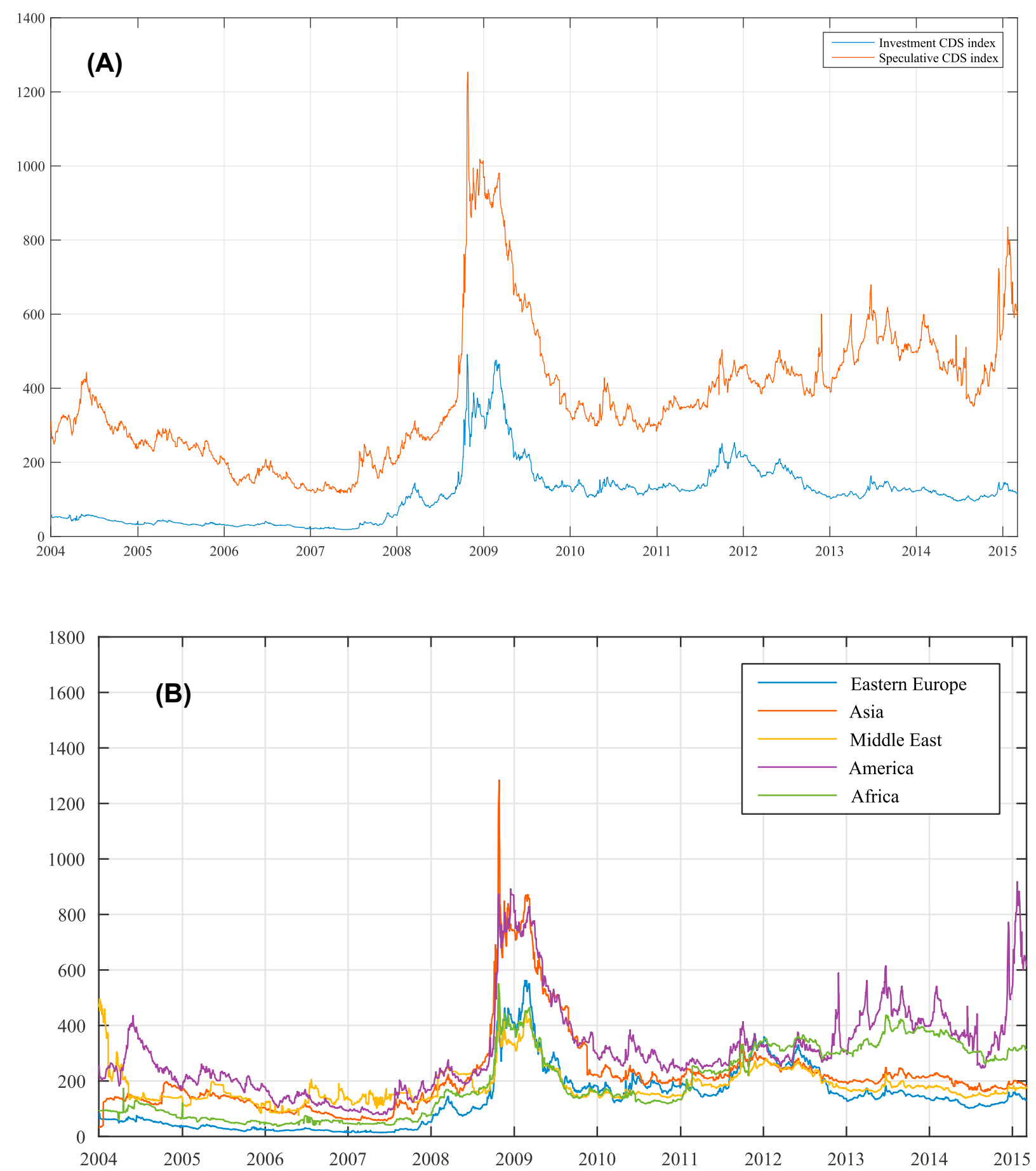

Fig. 1. Daily time evolution of CDS spreads.

This figure represents, in Panel A, the daily time evolution of two market benchmark CDS indexes built based on each country's rating grade category, calculated as the average CDS spreads for all countries within the same investment or speculative grade. Panel B shows the daily time evolution of the CDS spreads of the five portfolios, calculated as the average of all emerging countries' CDS spreads that are included in the same portfolio. The sample period is from January 1, 2004 to March 4, 2015. 
rating designations considered as low credit quality (between $\mathrm{BB}+$ to $\mathrm{SD}$ ), the latter is built with the credit rating designations considered as high or medium credit quality (those between AAA and BBB-).

At first glance, one observes substantial differences in CDS spreads, both in the portfolios and the individual countries. ${ }^{8}$ The maximum values in the sample are observed for the Asia and America portfolios with 1285.65 bps (due to Pakistan and Sri Lanka) and 919.55 bps (due to Venezuela and Argentina), respectively. There is a notable difference in the average CDS spreads, from a low of 135.46 bps for Eastern Europe (with the sample's lowest average found in Czech Republic) to a maximum of 307.50 bps for the America portfolio (where Venezuela and Argentina provide the sample's highest means). The effect of the 2008 global financial crisis is evident in the marked increase in CDS premiums in that year. It affected all portfolios, though with a greater impact in Asia and America. While the value of CDS premiums did drop significantly after 2009, they have not returned to pre-crisis levels. Overall, all portfolios display a quite stable pattern with the exception of America, which experiences a considerably intense rise after 2012, reflecting the Argentine and Venezuelan credit risk troubles.

In this work, we consider a credit rating event to have occurred under three circumstances: first, the actual credit rating of a country is altered; second, there is a modification in its review for a credit rating change; finally, the country is placed on a watch-list for a potential alteration to its credit rating. Positive (negative) rating events are those in which the sovereign's letter credit rating assigned by S\&P is upgraded (downgraded), or its credit outlook is revised, which includes movements with respect to S\&P's credit watch-list.

The credit rating event data are presented in Table 2, with Panel A showing the distribution per country and portfolio, and Panel B providing a breakdown of credit rating events per year. In our sample of 45 sovereign emerging economies, the number of credit rating announcements totals 418, with a modest asymmetry observed in favor of positive events (rating upgrades), which number 224, compared to negative events (rating downgrades), which total $194 .^{9}$ A similar pattern is observed in the Eastern Europe and Middle East portfolios, where the quantity of ratings upgrades and downgrades are for the most part equally balanced. However, an asymmetrical relationship is found in the three remaining portfolios. Whereas positive rating events are the majority in the Asia and America portfolios, credit downgrades prevail in Africa. One further observation is that, prior to 2008, negative events are clearly outnumbered by positive ones. In 2008, however, the effect of the global financial crisis leads to a reversal in the trend and credit downgrades take the lead. Furthermore, the total number of rating events reaches a peak in 2008 , as do the quantity of downgrades. The jump in negative rating events that occurs in 2008 is clearly connected to the emerging economies' credit worthiness, observed in Fig. 1 as an increase in the average CDS spreads. In addition, it highlights the greater vulnerability of countries with the speculative-grade category.

\section{Hypotheses}

This section presents the hypotheses to be tested in the paper. The first of the hypotheses is directly related to the main objective of this study, which is to find empirical evidence supporting the notion that sovereign ratings significantly affect cross-border emerging CDS markets. If market participants view rating news as country-specific, no transmission effects would be observed in non-event countries. However, the global financial crisis of 2008 has highlighted the fact that understanding the existing connections between markets is key in order to understand and prevent financial crises and their evolution. Rating announcements provide new information about a country which can intensify the connections across countries, a particularly significant effect in emerging economies with more evident problems of transparency and information asymmetry. This statement is consistent with findings reported by several studies that CDS spreads can be explained by common factors (Remolona \& Scatigna, 2008; Ballester et al., 2016; Longstaff et al., 2008) linked to global economic fundamentals and investors' risk appetite. In that case, rating events will be transmitted to other sovereign CDS markets. This leads to the first hypothesis:

H1. Sovereign ratings significantly spill over to cross-border emerging CDS markets.

Next, we evaluate to what extent the findings support the notion that spillover effects differ based on distinct features. As in earlier works (see Gande \& Parsley, 2005; Baum et al., 2016; or Drago and Gallo, 20,016, among others), we expect to observe an asymmetric reaction to positive and negative credit rating events. The aim is to analyse whether the number and impact of statistically detected cross-border effects associated with downgrades is greater than the upgrades or not, bringing us to the second hypothesis:

H2. CDSs in non-event countries respond asymmetrically to upgrades and downgrades.

By analysing the two types of credit rating events (positive/negative) separately, we are able to differentiate two sorts of reactions to rating events (positive or negative) and two different effects (spillover and competitive) among emerging economies. Additionally, since the existence of negative spillover effects in response to downgrades are especially sensitive due to the fact that they could fuel downturns and heighten financial instability, we therefore hypothesize that:

H3. Downgrades have significant negative spillover effects on the CDS markets of other sovereigns.

The aim of this third hypothesis is to assess whether there is reason to believe that the concerns of policymakers about negative

\footnotetext{
${ }^{8}$ Since the 45 emerging countries considered in the study represent a very heterogeneous sample, the significant differences between the descriptive statistics are not unexpected.

${ }^{9}$ If we observe the type of event, the pattern is similar, with a greater number of favourable rating changes (106) compared to unfavourable ones (65) and positive outlooks (118) exceeding negative ones (108). In contrast, only downgrades (21) are observed with regard to the credit watch-list. The authors can provide these results, which are not included in the work.
} 
Table 2

The distribution of sovereign credit rating events.

\begin{tabular}{|c|c|c|c|c|c|c|c|}
\hline Portfolio/Country & Upgrades & Downgrades & Total & Portfolio/Country & Upgrades & Downgrades & Total \\
\hline Eastern Europe & 60 & 66 & 126 & Middle East & 28 & 24 & 52 \\
\hline Bulgaria & 7 & 7 & 14 & Bahrain & 3 & 8 & 11 \\
\hline Czech Republic & 4 & 0 & 4 & Israel & 5 & 1 & 6 \\
\hline Estonia & 8 & 8 & 16 & Lebanon & 4 & 8 & 12 \\
\hline Hungary & 2 & 15 & 17 & Qatar & 3 & 1 & 4 \\
\hline Lithuania & 8 & 12 & 20 & Turkey & 9 & 5 & 14 \\
\hline Poland & 6 & 2 & 8 & Saudi Arabia & 4 & 1 & 5 \\
\hline Romania & 7 & 4 & 11 & America & 69 & 37 & 106 \\
\hline Russia & 6 & 7 & 13 & Argentina & 4 & 9 & 13 \\
\hline Slovakia & 10 & 2 & 12 & Brazil & 10 & 2 & 12 \\
\hline Slovenia & 2 & 9 & 11 & Chile & 5 & 0 & 5 \\
\hline Asia & 58 & 33 & 91 & Colombia & 6 & 0 & 6 \\
\hline China & 10 & 0 & 10 & Costa Rica & 1 & 1 & 2 \\
\hline India & 5 & 2 & 7 & Dominican Republic & 4 & 5 & 9 \\
\hline Indonesia & 10 & 2 & 12 & El Salvador & 0 & 5 & 5 \\
\hline Kazakhstan & 6 & 5 & 11 & Guatemala & 2 & 2 & 4 \\
\hline Pakistan & 5 & 7 & 12 & Mexico & 5 & 2 & 7 \\
\hline Philippines & 7 & 4 & 11 & Panama & 7 & 0 & 7 \\
\hline Malaysia & 1 & 1 & 2 & Peru & 11 & 0 & 11 \\
\hline Thailand & 1 & 3 & 4 & Uruguay & 9 & 0 & 9 \\
\hline South Korea & 3 & 0 & 3 & Venezuela & 5 & 11 & 16 \\
\hline Sri Lanka & 5 & 5 & 10 & Africa & 9 & 34 & 43 \\
\hline \multirow[t]{5}{*}{ Vietnam } & 5 & 4 & 9 & Egypt & 2 & 14 & 16 \\
\hline & & & & Ghana & 0 & 4 & 4 \\
\hline & & & & Morocco & 5 & 3 & 8 \\
\hline & & & & South Africa & 2 & 5 & 7 \\
\hline & & & & Tunisia & 0 & 8 & 8 \\
\hline \multicolumn{8}{|c|}{ Panel B: The distribution of credit rating events per year } \\
\hline Year & & Upgrades & & Downgrades & & Total & \\
\hline 2004 & & 29 & & 2 & & 31 & \\
\hline 2005 & & 42 & & 6 & & 48 & \\
\hline 2006 & & 32 & & 11 & & 43 & \\
\hline 2007 & & 23 & & 10 & & 33 & \\
\hline 2008 & & 13 & & 46 & & 59 & \\
\hline 2009 & & 12 & & 18 & & 30 & \\
\hline 2010 & & 24 & & 5 & & 29 & \\
\hline 2011 & & 20 & & 28 & & 48 & \\
\hline 2012 & & 10 & & 27 & & 37 & \\
\hline 2013 & & 10 & & 21 & & 31 & \\
\hline 2014 & & 8 & & 10 & & 18 & \\
\hline 2015 & & 1 & & 10 & & 11 & \\
\hline Total & & 224 & & 194 & & 418 & \\
\hline
\end{tabular}

This table presents the distribution of the credit rating events per country and portfolio (Panel A) and per year (Panel B), distinguishing between positive and negative events for all the 45 emerging countries and five portfolios. The sample period is from January 1, 2004 to March 4, 2015.

spillover effects due to downgrades are not unfounded. Nevertheless, we argue that even though this potential negative effect is likely to be found in the wake of sovereign downgrades during crisis periods (see Kaminsky \& Schmukler, 2002), it is not clear that a similar negative spillover effect would occur during tranquil times (Ismailescu \& Kazemi, 2010). In fact, following Wengner et al. (2015), if we assume that non-event emerging economies are competitors, we can put forward the following hypothesis:

H4. Competitors benefit (suffer) from credit downgrades (upgrades) in terms of decreasing (increasing) CDS spreads.

Finally, according to Kaminsky and Schmukler (2002) and Böninghausen and Zabel (2015) spillover effects are stronger at the regional level. This finding suggests that cross-border effects are likely to differ across regions, which provides motivation to examine 
the market reaction to rating announcements at the portfolio and intra-portfolio levels. ${ }^{10}$ With this distinction, we intend to determine whether the cross-border response of the CDS market is significantly different when the analysis is carried out between international emerging portfolios based on geographical location or between countries that belong to the same portfolio. This leads to the following hypothesis:

H5. CDS market cross-border reactions to sovereign credit rating events differ across regions.

\section{Methodology}

The methodology we use is the standard one for an event study (Finnerty et al., 2013; Hull et al., 2004; Kothari \& Warner, 1997; Norden \& Weber, 2004), though it is adapted to check for the existence of cross-border impacts. Specifically, we test the cumulative abnormal returns (CARs) of one emerging economy (either at the portfolio level or at the country level) in the time period around the date of a credit rating event in another economy. We aim to study if the occurrence of a rating announcement affecting one emerging economy spills over onto the CDS spreads of neighbouring emerging economies.

The methodology follows an empirical procedure consisting of two stages. The initial stage is to calculate the abnormal return of each emerging economy CDS series $i$ at each day $t$ by employing the expression:

$$
A R_{i t}=\Delta C D S_{i t}-\Delta \operatorname{Index} C D S_{t}
$$

where $\triangle C D S_{i t}$ is the increase in the credit spread at time $t$ for emerging economy $i$, and the market factor is represented by the benchmark Index $C D S_{t}$.

Following Jorion and Zhang (2007), Afonso et al. (2012) and Abad et al. (2018), we calculate the daily benchmark index, grouping each day the countries of the sample into two rating grade categories, investment and speculative grade. The first contains the credit rating designations considered as high or medium credit quality (those between AAA and BBB-), while the second contains the credit rating designations considered as low credit quality (those from $\mathrm{BB}+$ to SD). ${ }^{11}$ Thus, the adjusted increase in the CDS spread is measured by taking the absolute increase in the sovereign CDS spread for emerging economy $i$ and subtracting the increase in a benchmark CDS spread, in order to control for variations in the sovereign CDS market conditions.

The next stage involves determining the CAR by using the CDS abnormal returns and applying the expression:

$$
C A R_{i\left(t_{1}, t_{2}\right)}=\sum_{t=t_{1}}^{t_{2}} A R_{i t}
$$

where $\left(t_{1}, t_{2}\right)$ represents the window for which we examine if the rating upgrade or downgrade affecting a specific emerging economy produces any transmission effects on the sovereign CDS spreads of neighbouring emerging economies. In agreement with previous literature, we analyse the three-trading-day window $[-1,1]$ around the announcement date, where the credit rating event date is considered the day zero. The length of the event window is chosen to account for asynchronous trading. ${ }^{12}$

We have also controlled for the effect of contamination events and we work with clean events, that is, with non-overlapping events within the 3-day window. In this manner, we ensure that we are analysing the effect of only one rating change in each event, that is, we require that there be no events in any rated country within the estimation window. Not to control for these cases could seriously bias estimation findings. In the end, we work with 258 uncontaminated events, 149 upgrades and 109 downgrades (Table 3).

We look for evidence of cross-border effects through a range of analyses. ${ }^{13}$ First, we study the possible cross-border impact averaged across all the sample's emerging countries and ratings events. Next, we do the same at the portfolio level, looking for cross-border effects among emerging economies that belong to different regions. More concretely, we look for the existence of effects on average through all the portfolios, but not only that, we also analyse which of the five representative portfolios considered, if any, are driving the transmission process. To do this, we study the transmission from each event portfolio to all the non-event portfolios, as well as the pairwise

\footnotetext{
10 To the best of our knowledge, this study is the first that has built emerging geographic portfolios to test to what extent the existence of spillovers is related to a regional factor.

${ }^{11}$ The use of this rating-grade CDS index to calculate the abnormal returns enables us to control much better for variations in the sovereign CDS market conditions, as proxied by the same investment or speculative rating grade. Alternatively, we calculate the market index by finding the mean of all the CDSs employed in the study (suggested by Ismailescu \& Kazemi, 2010). The cross-border effects derived from the use of this alternative index are in general similar to the ones obtained initially. It should be noted that some effects disappear and new ones appear, the latter related to a specific group of events produced in countries in the investment or speculative category. We attribute the differences to the fact that with the rating-grade index the abnormal returns are more precise since the market index better captures the level of credit risk by differentiating by investment and speculative categories. Results are omitted due to space considerations.

${ }_{12}$ In addition, we repeat all the estimations within a [-5,5] window. To preserve space, the results are upon request.

${ }^{13}$ In accordance with Boehmer et al. (1991), we employ the usual $t$-test to check for the absence of effects. This test allows for changing variances by using the cross section of cumulative abnormal returns to form an estimator of the variance. For this estimator to be consistent we require the abnormal returns to be uncorrelated in the cross section. This is not an issue in our applications since cross-border spillover analysis with clean events are carried out. Note that cross-sectional homoscedasticity is not required for consistency. We utilise the non-parametric Wilcoxon signed-rank test to check the robustness. The overall findings do hold, although with some differences, especially at the intra-regional level. Results are omitted due to space consideration.
} 
Table 3

The distribution of sovereign clean credit rating events.

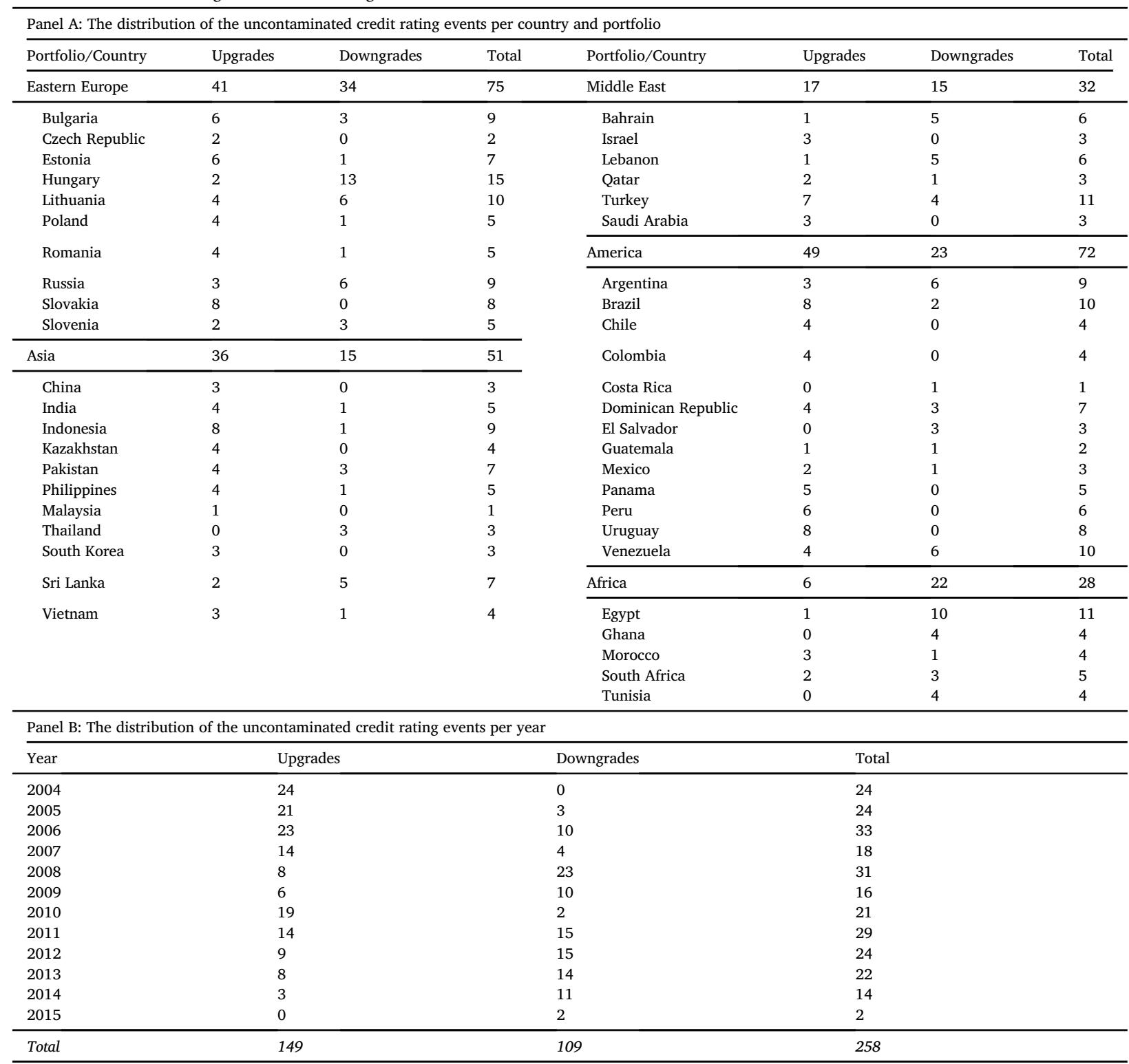

This table presents the distribution of the uncontaminated credit rating events per country and portfolio (Panel A) and per year (Panel B), distinguishing between positive and negative events for all the 45 emerging countries and five portfolios. The sample period is from January 1 , 2004 to March 4, 2015.

effect. Subsequently, we look within each portfolio for evidence of cross-border effects across all the countries that make up the portfolio and from the event country to all others in the same portfolio. Given the likelihood that countries in the same portfolio compete with one another, we posit that cross-border effects are more likely to be observed at this level.

Distinguishing between positive and negative credit rating events, we are able to differentiate two sorts of reactions (positive or negative) and two different effects (spillover and competitive) among emerging economies. More specifically, the four cross-border effects that are tested are explained below and summarized in Table 4.

- The observation that upgrades in a particular economy occur before a significant and negative CAR is a sign of a decrease in sovereign CDSs of non-event economies on average, which means an improvement in their sovereign credit risk. It implies a positive cross-border effect due to upgrades and, hence, they are regarded by investors as substitute assets. Therefore, a positive spillover effect associated with upgrades is present, which we denote by $+/ \mathrm{SE} / \mathrm{U}$. 
Table 4

Cross-border relationships.

\begin{tabular}{lll}
\hline & Upgrades & \\
\hline (-) CAR & $(+)$ CAR & $(-)$ CAR \\
Decrease CDS & Increase CDS & Decrease CDS \\
Positive Effect & Negative Effect & Positive Effect \\
Spillover effect & Competition effect & Competition effect \\
$+/$ SE/U & $-/$ CE/U & $+/ C E / D$ \\
\hline
\end{tabular}

This table summarises the types of significant cross-border effects that we can find in the event study analysis when we examine whether sovereign credit rating events in a given emerging economy have any impact on the CDSs of cross-border emerging economies. CAR denotes the value of the cumulative abnormal return around the credit rating event date. SE and CE denote the spillover and competition effects, while + or - denote whether the cross-border effect is positive or negative, respectively.

- The observation that upgrades in a particular economy occur before a significant and positive CAR is a sign of an increase in sovereign CDSs of non-event economies on average, which means a worsening in their sovereign credit risk. It implies a negative crossborder effect due to upgrades and, hence, they are regarded by investors as non-substitute assets. Therefore, a negative competition effect associated with upgrades is present, which we denote by -/CE/U.

- The observation that downgrades in a particular economy occur before a significant and negative CAR is a sign of a decrease in sovereign CDSs of non-event economies on average, which means an improvement in their sovereign credit risk. It implies a positive cross-border effect due to downgrades and, hence, investors see cross-border economies as non-substitute assets. Therefore, a positive competition effect associated with downgrades is present, which we denote by $+/ C E / D$.

- The observation that downgrades in a particular economy occur before a significant and positive CAR is a sign of an increase in sovereign CDSs of non-event economies on average, which means a worsening in their sovereign credit risk. It implies a negative cross-border effect due to downgrades and, hence, investors see cross-border economies as substitute assets. Therefore, a negative spillover effect associated with downgrades is present, which we denote by -/SE/D. ${ }^{14}$

\section{Results}

In this section the impact of rating announcements on the sovereign CDS market is examined. We start the analysis by looking for the existence of cross-border effects averaged across all the economies and events analysed in the study. In none of the cases are any significant results found. ${ }^{15}$ Undeniably, a marked heterogeneity does exist among the forty-five emerging economies that we analyse, thus we are not surprised to observe the lack of spillover impacts on the CDS market from rating announcements when these markets are analysed as a group. However, we cannot conclude from this that no cross-border relationship exists among some specific economies or regions. It seems likely that when considering them on average all together the existing effects cancel out. This finding reinforces the construction of international emerging CDS portfolios with the aim of examining whether there is a significant CDS market reaction to rating announcements, either at the portfolio level or between countries belonging to the same portfolio. Tables 5 and 6 report the empirical results, while Fig. 2 summarises the main effects to facilitate the discussion.

\subsection{Cross-border spillover effect at the portfolio level}

We consider the five representative emerging CDS portfolios previously constructed (Africa, America, Asia, Eastern Europe, and Middle East) and we first analyse the existence of cross-border effects on average across all the portfolios. Panel A in Table 5 exhibits the results, where we did not find any significant effect, neither in upgrades nor in downgrades.

The next step is to examine the impact of credit rating events in a specific portfolio on the remaining ones. Our goal is to isolate each transmitting portfolio to determine if its sovereign ratings announcements produce observable cross-border effects, on average, in the other portfolios analysed as a group. Panel B in Table 5 displays the results. The only significant effect detected is due to Asia, which shows a positive competitive effect caused by downgrades. The negative CAR value indicates that portfolios not targeted by the credit rating event see a positive change, on average, in their sovereign credit risk rating. This means that credit deterioration in Asia leads to a positive change in the credit risk of cross-border sovereign economies.

In order to identify which emerging portfolios are the receivers of the positive competitive effect due to downgrades in Asia found above, we perform a pairwise analysis. Panel C in Table 5 shows that Middle East and Africa benefit under negative credit news in Asia. Given this result, we could expect that those investors interested in investing in the sovereign debt of emerging countries will modify their decisions in the wake of a downgrade in the Asian region. Specifically, the funds will move to the markets of Middle East or Africa, which will experience a drop in their credit risk levels. We also observe two additional effects led by upgrades in Asia, which have a positive (negative) effect on Eastern Europe (Africa). This indicates that Eastern Europe (Africa) benefits (is harmed) by positive events

\footnotetext{
$\overline{14}$ Note that the case of a negative spillover due to downgrades is especially sensitive considering that it implies that problems in one economy leads to problems in other emerging countries, fuelling downturns.

${ }^{15}$ As the results are not significant they are not reproduced here, but the authors will provide them if requested.
} 
Table 5

Cross-border effects at the portfolio level.

\begin{tabular}{|c|c|c|c|c|c|}
\hline \multicolumn{6}{|c|}{ Panel A. Total Spillover: Through all the portfolios } \\
\hline Upgrades & & & & & 0.387 \\
\hline Downgrades & & & & & -0.677 \\
\hline \multicolumn{6}{|c|}{ Panel B. Directional Spillover from each portfolio to the rest } \\
\hline & Eastern Europe & Asia & Middle East & America & Africa \\
\hline Upgrades & 1.518 & -0.237 & -0.143 & 0.242 & -0.916 \\
\hline Downgrades & 0.834 & $-6.244 * *$ & 0.080 & -1.216 & 0.827 \\
\hline $\mathrm{E} / \mathrm{S}$ & & {$[+/ \mathrm{CE}]$} & & & \\
\hline \multicolumn{6}{|c|}{ Panel C : Pairwise Spillover } \\
\hline From Eastern Europe to & Asia & Middle East & America & Africa & \\
\hline Upgrades & 0.998 & 2.629 & 0.707 & 1.737 & \\
\hline Downgrades & -2.480 & 3.443 & 2.693 & -0.320 & \\
\hline From Asia to & Eastern Europe & Middle East & America & Africa & \\
\hline Upgrades & $-1.013^{*}$ & -0.582 & 0.905 & $1.552^{*}$ & \\
\hline $\mathrm{E} / \mathrm{S}$ & {$[+/ \mathrm{SE}]$} & & & [ -/CE] & \\
\hline Downgrades & -1.346 & $-8.095^{*}$ & -2.771 & $-12.763^{* *}$ & \\
\hline $\mathrm{E} / \mathrm{S}$ & & {$[+/ \mathrm{CE}]$} & & {$[+/ \mathrm{CE}]$} & \\
\hline From Middle East to & Eastern Europe & Asia & America & Africa & \\
\hline Upgrades & 0.682 & 1.191 & -1.102 & -1.342 & \\
\hline Downgrades & -0.785 & $-2.332^{*}$ & 0.151 & $3.278^{*}$ & \\
\hline $\mathrm{E} / \mathrm{S}$ & & {$[+/ \mathrm{CE}]$} & & {$[-/ \mathrm{SE}]$} & \\
\hline From America to & Eastern Europe & Asia & Middle East & Africa & \\
\hline Upgrades & 0.533 & -0.664 & 1.095 & 0.003 & \\
\hline Downgrades & 0.025 & -2.810 & -0.189 & -1.887 & \\
\hline From Africa to & Eastern Europe & Asia & Middle East & America & \\
\hline Upgrades & -0.718 & -2.007 & -1.191 & 0.253 & \\
\hline Downgrades & 1.903 & -0.017 & 1.126 & 0.297 & \\
\hline
\end{tabular}

This table presents the total mean spillover effects across all the portfolios and rating events (Panel A), the directional spillover from each portfolio to the rest of the portfolios (Panel B), and the pairwise spillover (Panel C), differentiating the events into upgrades or downgrades. We show the average cumulative abnormal returns (CAR) and the significance level employing the usual $t$-test, at the $10 \%(*), 5 \%(* *)$ or $1 \%$ level $(* * *)$. The sample period is from January 1, 2004 to March 4, 2015 for a total of five representative portfolios constructed from the 45 available emerging countries. We consider the $[-1,1]$ window around the event date, where the event date is day zero. E/S denotes the type of the effect (when significant): SE (CE) means spillover (competition) effect, while $+(-)$ indicates a positive (negative) spillover.

that occur in Asia.

Finally, pairwise spillover analyses are also performed, choosing each of the remaining portfolios as the transmitter. Even though they have not been identified as transmitters to others in average terms, it could be the case that some of them show significant spillover effects in pairs. The findings indicate that the previously discussed relationship between Asia and Middle East is actually bidirectional, in that both regions respond positively to credit deteriorations in the other's portfolio. Finally, we observe how Africa suffers from downgrades in the Middle East portfolio (Table 5, Panel C). The positive CAR value implies that Africa's sovereign credit risk worsens in response to negative events in Middle East. This is the only case of negative spillover due to downgrades found to date. This result implies that international investors see both regions as substitutes. Sovereign downgrades in Middle East also harm Africa, which will make it difficult for both countries to access financing.

To sum up, there is enough evidence of cross-border market reactions to rating events between sovereign emerging economies to support H1, which reinforces our argument that rating announcements do have an impact across regions and not just in the re-rated country, as the traditional literature has asserted. Furthermore, significant asymmetries are found supporting H2, since CDSs in nonevent portfolios respond asymmetrically to upgrades and downgrades. Overall, rating events in Asia and Middle East are associated with a competitive effect, which supports $\mathrm{H} 4$. This indicates that, at least internationally, for portfolios of emerging economies, and for a period that includes periods of crisis and non-crisis, spillover effects are not the predominant effects. In fact, we only observe a negative spillover effect across portfolios, from Middle East to Africa, which should be guarded against by policymakers and investors who have an interest in the African debt market (in this specific case, we do not find support for $\mathrm{H} 4$ based on our results, but we do find support for H3). The findings are also consistent with H5. It is evident that CDS market cross-border reactions to sovereign credit rating events differ 
Table 6

Cross-border effects within each portfolio.

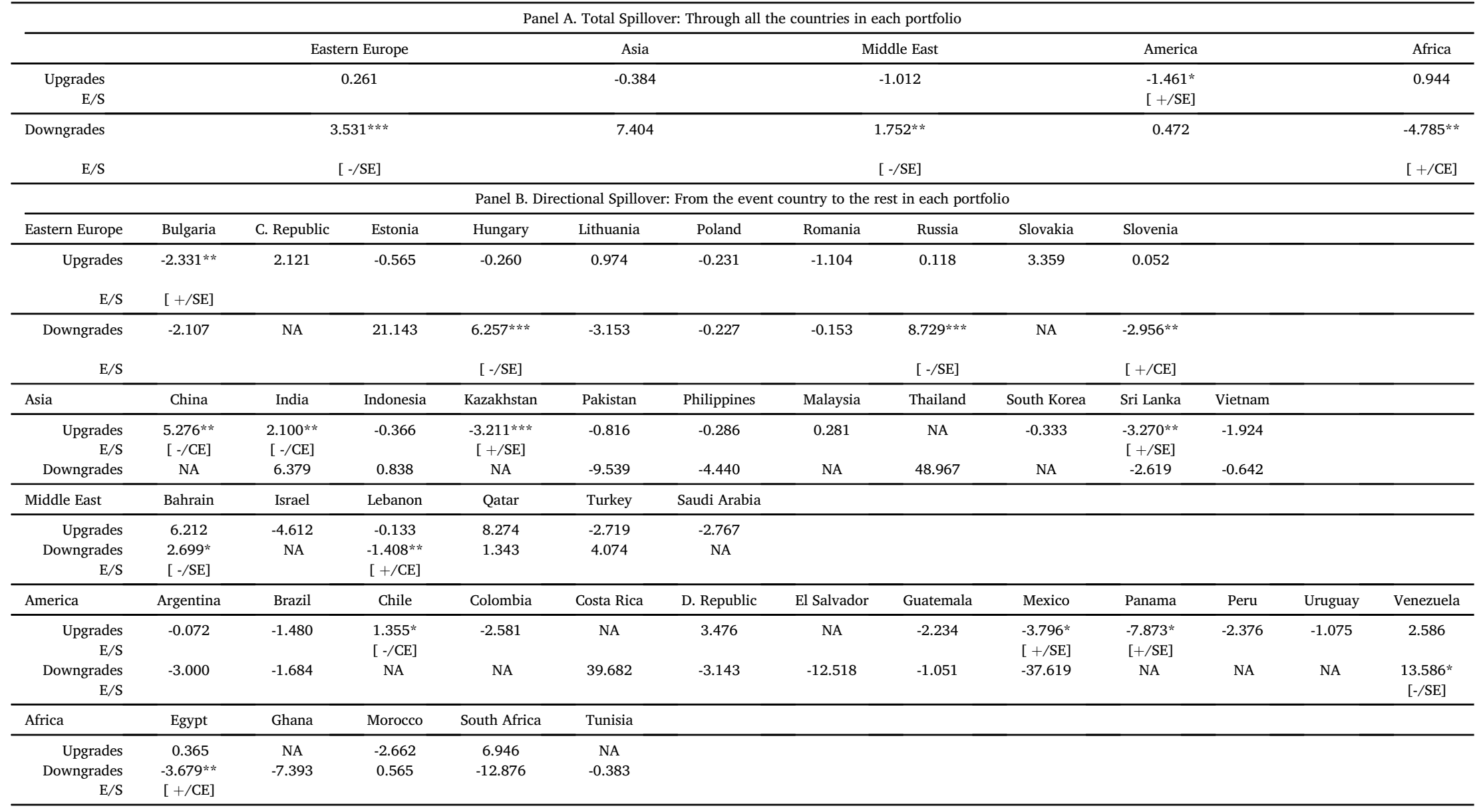

This table presents the total mean spillover across all the countries and rating events in each portfolio (Panel A) and the directional spillover from each country to the rest inside each portfolio (Panel B),

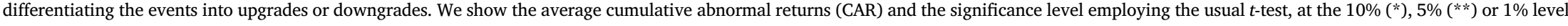
$(* * *)$. The sample period is from January 1, 2004 to March 4, 2015 for a total of five representative portfolios constructed from the 45 available emerging countries. We consider the [-1,1] window around

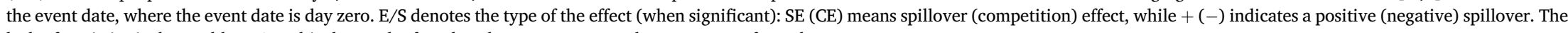
lack of statistics is denoted by NA and is due to the fact that there are not enough events to perform the test. 


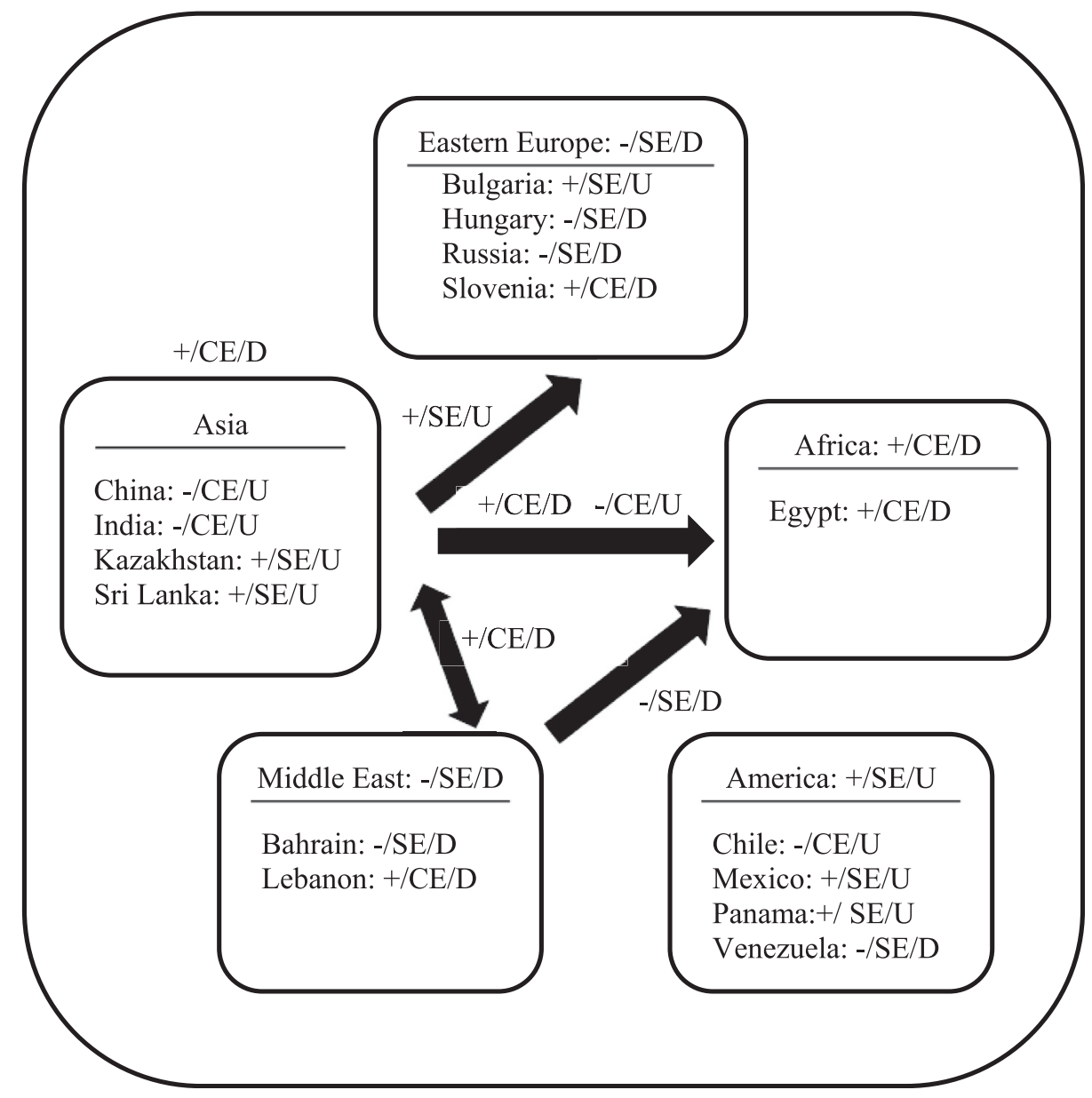

Fig. 2. Cross-border effects at the portfolio level and within each portfolio.

This figure presents the different cross-border effects at the portfolio level and across all the countries and rating events found, differentiating the events into upgrades or downgrades. CE (SE) means the competition (spillover) effect, while $+(-$ ) indicates a positive (negative) spillover. At the portfolio level, the only significant effect detected is due to Asia, which shows a positive competitive effect caused by downgrades (+/CE/D). This effect is transmitted specifically to Middle East and Africa, which benefit from the negative credit news in Asia. We also observe two additional effects led by upgrades in Asia, which have a positive (negative) effect on Eastern Europe (Africa), +/SE/U and -/CE/U respectively. This indicates that Eastern Europe (Africa) benefits (is harmed) by positive events that occur in Asia. Finally, we observe how Africa suffers from downgrades in the Middle East portfolio (-/SE/D). This is the only case found of negative spillover due to downgrades. Moreover, we show the countries within each portfolio that exhibit a significant directional spillover to the rest of the countries inside a specific portfolio. These effects are tested using the significance level employing the usual $t$-test, at the $10 \%(*), 5 \%(* *)$ or $1 \%$ level $(* * *)$.

across regions. In this regard, it is notable that America is the only emerging portfolio without receiving or transmitting cross-border effects, possibly due to the idea that distance is inversely related to spillovers. ${ }^{16}$

\subsection{Cross-border spillover effect within each portfolio}

After providing evidence for the existence of cross-border effects due to rating events between international emerging economies at the portfolio level, this section carries out an analysis within each portfolio. In our opinion, there is a greater probability of finding crossborder impacts when economies are geographically located in the same region. Due to these countries having a similar economic environment, we suspect that the potential effects should be more pronounced and that differences in the quality of credit may affect the refinancing conditions of nearby economies not targeted by the credit rating event. However, the type and direction of the effect is not clear. It is quite possible to find competitive effects if we assume that non-event emerging economies that belong to the same geographical area are competitors, but a spillover effect between neighbours with similar economic fundamentals cannot be dismissed. Therefore, we are likely to find different cross-border relationships across regions, which are also expected to be different to the ones

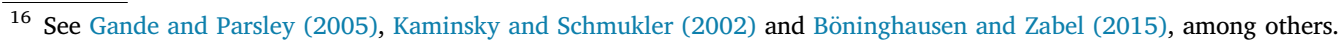


previously found among portfolios.

Table 6 displays the results. Overall, we find evidence of significant cross-border effects around the rating event date inside all the portfolios, which is consistent with H1. Again, this indicates that the analysis of the effect of rating announcements should not be limited to the re-rated country, but also across countries. Furthermore, we identify important asymmetries that support H2, with different conclusions depending on the portfolio. While most intra-portfolio effects are due to upgrades in Asia and America, the effects associated with downgrades predominate in Eastern Europe, Africa and Middle East. Therefore, the disparate responses of the market to rating events across regions lends support to hypothesis $\mathrm{H} 5$, which clearly indicates that the results related to cross-border effects should not be generalised and should be analysed separately for each region. Moreover, since distinct types of effects are obtained, there is not enough evidence to confirm hypotheses $\mathrm{H} 3$ and $\mathrm{H} 4$ (that point to a spillover or competitive effect as the dominant one), at least not in a general way. On the other hand, these results, together with those previously obtained at the portfolio level, are indicative of how cross-border effects at the local and international levels are the result of various effects and reactions. As a result, our findings indicate that generalising the cross-border response of the market to credit rating announcements is not the correct approach; instead, the analysis should be carried out at the international or regional level (that is, at the portfolio or intra-portfolio level) for future research.

A more in-depth analysis provides us with some interesting relationships that should be taken into account by local investors and policymakers. Especially important are the negative effects. With regard to upgrades, China and India, in Asia, and Chile, in America, should be closely monitored, given that improvements in the credit status of these nations lead to an increase in the credit risk of neighbouring countries located in the same geographical area. Furthermore, negative events in Hungary and Russia (Eastern Europe portfolio), Bahrain (Middle East portfolio) and Venezuela (America portfolio) involve a worsening in the credit position of cross-border economies. These are the only four countries that can contribute to intensifying the financial instability of bad times in neighbouring sovereign debt markets (within their corresponding geographical zones). They are the only ones that show a significant negative spillover effect due to downgrades, supporting $\mathrm{H} 3$.

Nevertheless, positive reactions should not be dismissed. Non-event countries in Eastern Europe, Asia and America benefit from upgrades in Bulgaria, Kazakhstan and Sri Lanka, and Mexico and Panama, respectively. Positive events in these countries seem to exacerbate boom financial cycles (in line with Kaminsky \& Schmukler, 2002 or Ferri et al., 1999). On the other hand, some countries exhibit intra-portfolio positive effects in the wake of downgrades: Slovenia in Eastern Europe, Lebanon in Middle East, and Egypt in Africa. Negative events in these countries positively affect non-event countries located in the same geographic area, with a lowering of their risk of default. Therefore, there is little support for downgrades being excessively destabilising if we consider a large number of countries and a large sample period that is not limited to crises.

\section{Robustness tests}

\subsection{Crisis versus tranquil period}

To understand whether our findings are biased by the large sample period used, we repeat the analysis for two different periods, distinguishing rating announcements produced during a financial crisis from other events during tranquil times. The crisis period goes from July 2007 to December20, $13,{ }^{17}$ where the number of downgrades (which total 80) exceeds the upgrades (which number 72 ) by $10 \%$. In the case of the non-crisis period, the asymmetry in favor of positive events is more pronounced compared to negative events (77 versus 29). We report in Fig. 3 the different cross-border effects obtained during the two periods. Overall, the findings illustrate that the impact of rating announcements is significantly different over the two analysed periods.

At the portfolio level, we observe a different market reaction on average across all the portfolios depending on the period. Emerging economies respond positively (negatively) to credit deteriorations in cross-border economies during the crisis (normal times). The positive competition effect associated with downgrades detected during the crisis is led by Asia, and the portfolios that benefit from negative events that occur in Asia are Africa and Middle East. We note that this effect previously observed for the full sample occurs only during the crisis. On the other hand, during normal times, Eastern Europe is the portfolio leading the negative spillover effect due to downgrades detected, and Asia, Africa and Middle East are the ones that are harmed. It should be noted that, contrary to what would be expected, this result is typical of the non-crisis period (since it is not obtained for either the full period or the crisis period). Although this finding goes against the literature, which has focused mostly on the bond market and exclusively on cross-country analysis, it is in line with our general result that cross-border reactions to rating events are significantly different at the international or regional level. Finally, we observe how America continues to be isolated from the rest of the regions in both the crisis and non-crisis periods, since it does not react to rating events produced in other portfolios, nor does it exhibit a transmitting behavior.

Looking at the results within each portfolio, we observe that, with some exceptions, in general terms the effects detected for the full sample are maintained only for the crisis period. In the non-crisis period no effects are observed within the Africa and Middle East portfolios and in the remaining portfolios no new effects not previously observed (either in the full sample or the crisis sample) arise. The countries identified as producing financial instability in emerging markets during the crisis period deserve special attention. Upgrades

\footnotetext{
17 We determine the crisis period taking into account the most relevant financial crises that have hit the world economy: the global financial crisis of 2008 and the Eurozone sovereign debt crisis. The beginning of the crisis period coincides with the outbreak of the US subprime crisis, while the end of the crisis corresponds with the Eurozone turning point. After 2014, most countries in the Eurozone began to exhibit growth levels in their GDP and many of them started to create employment. The joint GDP of the whole area grew by $1.4 \%$ and unemployment fell to $9.1 \%$ on average, with $3.8 \%$ in Germany, the lowest level in the Eurozone.
} 
Fig. 3. Cross-border effects: crisis versus tranquil period.

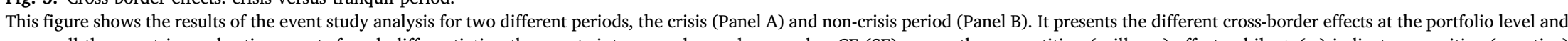
across all the countries and rating events found, differentiating the events into upgrades or downgrades. CE (SE) means the competition (spillover) effect, while $+(-)$ indicates a positive (negative) spillover. The significant cross-border effects detected in the main analysis are highlighted in bold. At the portfolio level, we document that emerging economies respond positively (negatively) to credit deteriorations in cross-border economies during crisis (normal times). The positive competition effect associated with downgrades ( + /CE/D) detected during the crisis period is led by Asia, and the

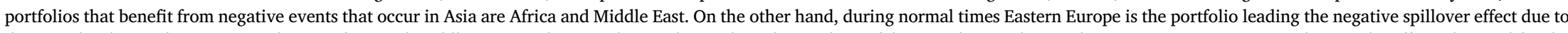
downgrades detected (-/SE/D), and Asia, Africa and Middle East are the ones that are harmed. Within each portfolio, we observe that, with some exceptions, in general terms the effects detected for the full sample are maintained only for the crisis period. These effects are tested using the significance level employing the usual $t$-test, at the $10 \%(*), 5 \%$ (**) or $1 \%$ level (***).

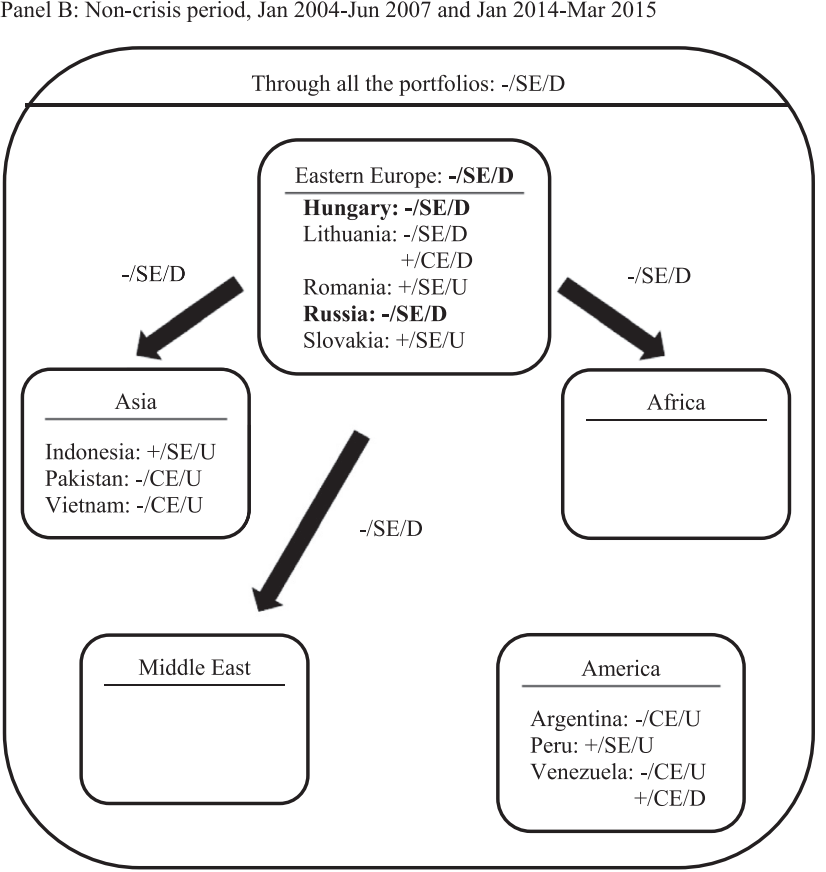


Fig. 4. Cross-border effects: investment versus speculative rating events.

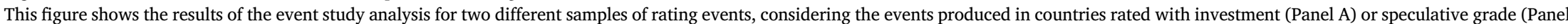

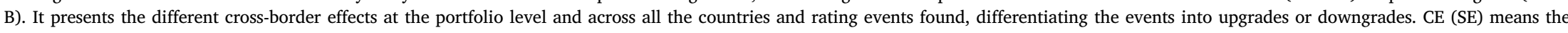

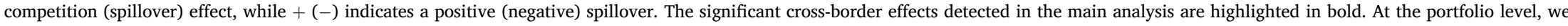
document that the positive competitive effect associated with downgrades (+/CE/D) in Asia affecting other regions on average detected for the full sample seems to be due to the investment-events. However, we cannot confirm that Africa and Middle East are also, in this case, economies that benefit from such downgrades. The other two effects in which Asia is leading the transmission and

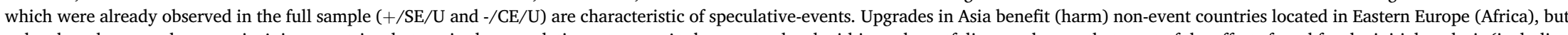
only when the upgrades occur in Asian countries that are in the speculative category. At the country level within each portfolio, we observe that most of the effects found for the initial analysis (including all events) are repeated either for the investment-events or for the speculative-events, but we cannot identify, at least in a general way, which type of effect is specific to each event group, as it varies depending on the region (portfolio) considered. These effects are tested using the significance level employing the usual $t$-test, at the $10 \%(*), 5 \%(* *)$ or $1 \%$ level $(* * *)$.

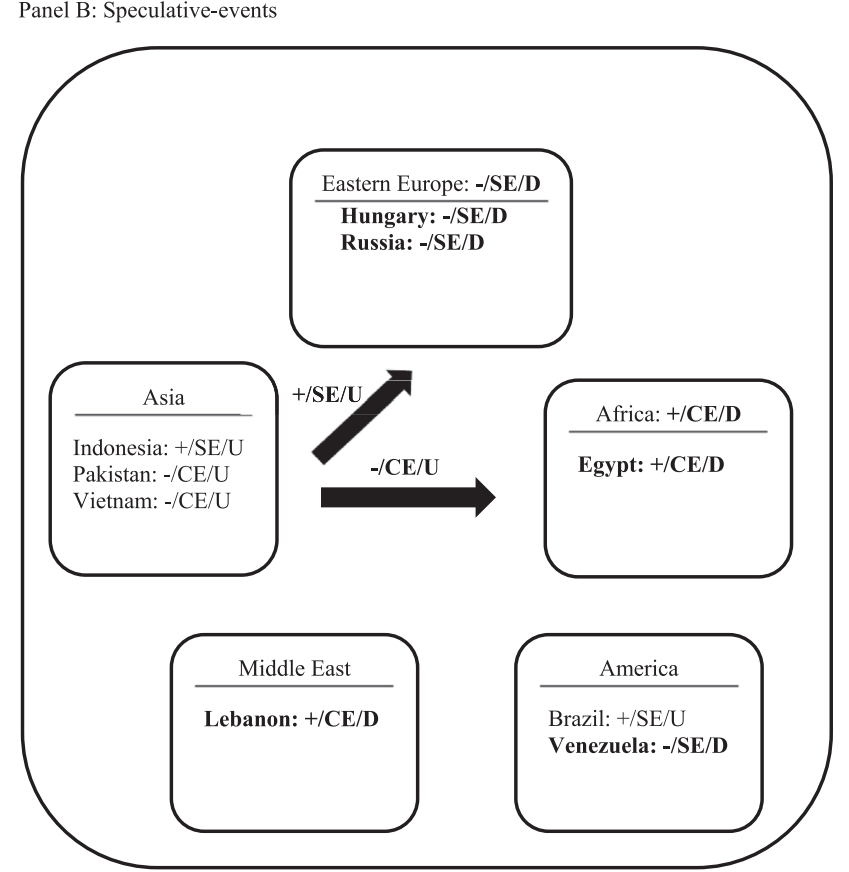


(downgrades) in China, India, Indonesia and Chile (Hungary, Bahrain and Venezuela) are those that have a negative impact on the remaining non-event countries that belong to the same region. These are exactly the same countries detected in the full-sample with a negative impact within the portfolio, except that Indonesia is now included (whose -/SE/D is only observed in crisis) and Russia disappears (whose -/SE/D is observed only in non-crisis).

\subsection{Investments versus speculative rating events}

In order to better understand our previous results, we divide our sample of rating events into two groups, distinguishing between events produced in countries rated with the investment or the speculative grade. The CDS spread behavior might be very different for the investment and speculative grades, so the market reaction may vary depending on whether the event is in one group or the other. We report in Fig. 4 the cross-border effects detected in both groups. Overall, we note that certain effects seem to be characteristic of a certain grade.

At the portfolio level, the positive competitive effect associated with downgrades in Asia affecting other regions on average detected for the full sample (and which was typical of the crisis period) seems to be due to the investment-events. However, we cannot confirm that Africa and Middle East are also in this case the economies that benefit from such downgrades that occur in Asian countries that are in the investment category. We do not have enough negative events in total in that category for Asia (there are only four) to be able to perform the pairwise test with guarantees. The other two effects in which Asia leads the transmission and which were already observed in the full sample, are characteristic of speculative-events. Upgrades in Asia benefit (harm) non-event countries located in Eastern Europe (Africa), but only when the upgrades occur in Asian countries that are in the speculative category. Finally, it should be noted how America continues to be isolated from other economies by not exhibiting any transmitting or receiving effects.

At the country level within each portfolio, we observe that most of the effects found for the initial analysis (including all events) are repeated either for the investment-events or for the speculative-events, but we cannot identify, at least in a general way, which type of effect is specific to each event group, as it varies depending on the region (portfolio) considered. For example, looking at the negative spillover effect associated with downgrades, we find it in the investment-events of Bahrain (transmitted to the remaining Middle East countries), in the speculative-events of Venezuela (to the rest of the countries of America), and within Eastern-Europe, in the speculative-events in Russia and in both groups of events in Hungary. On the other hand, non-event countries in Africa benefit from speculative downgrades in Egypt. Finally, a new effect appears in Brazil (which did not emerge when considering all events), as upgrades in Brazil positively affect non-event American countries, but only when the upgrades occur when Brazil is in the speculative category. Note that Brazil is the only BRIC country that did not appear as a transmitter in the main analysis. ${ }^{18}$

\subsection{Split the event sample into two groups: rating changes versus outlooks and watch-lists}

In our main analysis, all credit events are combined and examined together. As a robustness check, we split the event sample into two groups, RC and O\&W. The former encompasses the actual credit rating changes, whereas the latter includes the outlooks (when there is a modification in the country's review for a credit rating change) and watch-lists (when the country is flagged for a potential alteration to its credit rating). Fig. 5 summarises the cross-border effects found.

In relation to the analysis between portfolios, we observe that the relationships previously detected (including all types of events) are generally typical of the O\&W events. This is not surprising given our sample of events. To cite an example, we only have four negative RC in the case of Asia, which makes it impossible to perform the pairwise contrast. On the other hand, the intra-portfolio analysis reveals a lot of variability depending on the region considered. There are some countries previously identified as transmitters that no longer appear in either of the two groups. Some other countries lead cross-border effects for the first time, indicating new exclusive relationships for a specific group of events. For instance, this is the case for Brazil, which exhibits a positive spillover effect to the remaining countries within America, but only for positive RC. Note that, while Brazil is the only BRIC country that did not appear as a transmitter in the main analysis, this same effect also emerged when events were limited to speculative events. Therefore, this effect seems to be typical of events that have led to actual rating changes at a time when Brazil was in the speculative category. In addition, only Hungary and Russia maintain their initial intra-portfolio effects in both groups. Within the rest of the portfolios, those countries previously identified as regional transmitters are now only in a specific group of events. What we cannot do is attribute a certain type of effect to one or another group of events, at least in a general way, since there is a lot of variability depending on the region analysed. These results generally suggest that when it comes to detecting a certain country as a transmitter of a certain type of effect, it is essential to carry out the analysis separately for each region.

\subsection{Excluding the BRICs}

As a further robustness check, we repeat the analysis excluding BRIC countries (Brazil, Russia, India and China). Given their role as developing countries deemed to be at a similar stage of newly advanced economic development, on their way to becoming developed countries, we wonder if these countries may be driving the cross-border effects detected in the main analysis. We report the results in Fig. 6.

18 BRIC is a grouping acronym referring to the four developing countries (Brazil, Russia, India and China) with the most important emerging or recently industrialized economies on the planet, and which are considered to be at a similar stage of recent advanced economic development. 
Panel A: Rating changes events

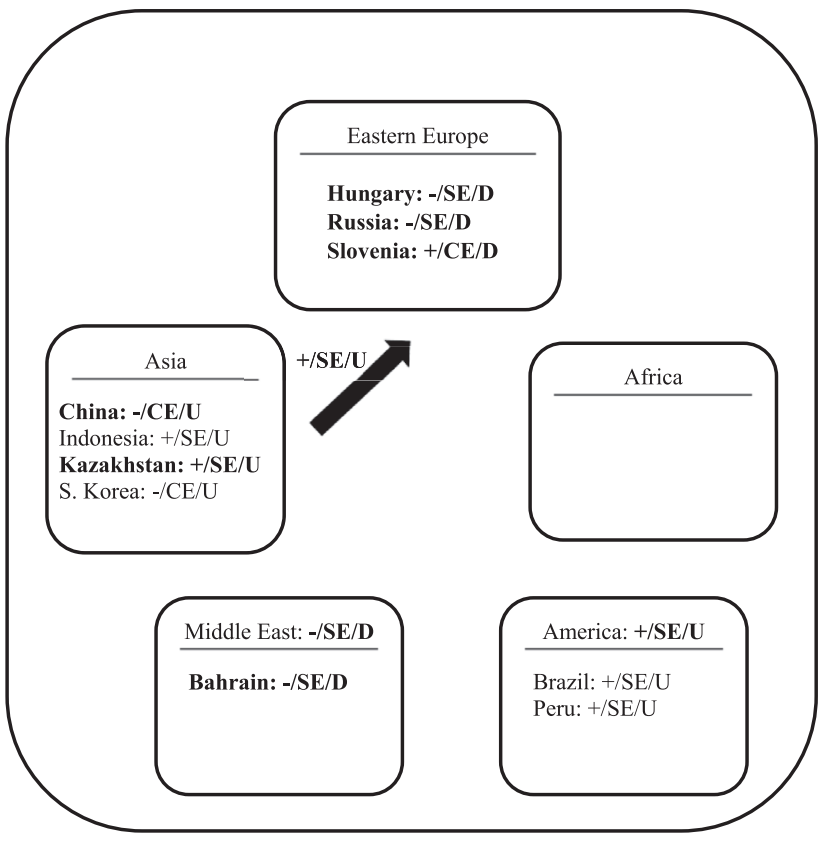

Panel B: Outlook and watch list events

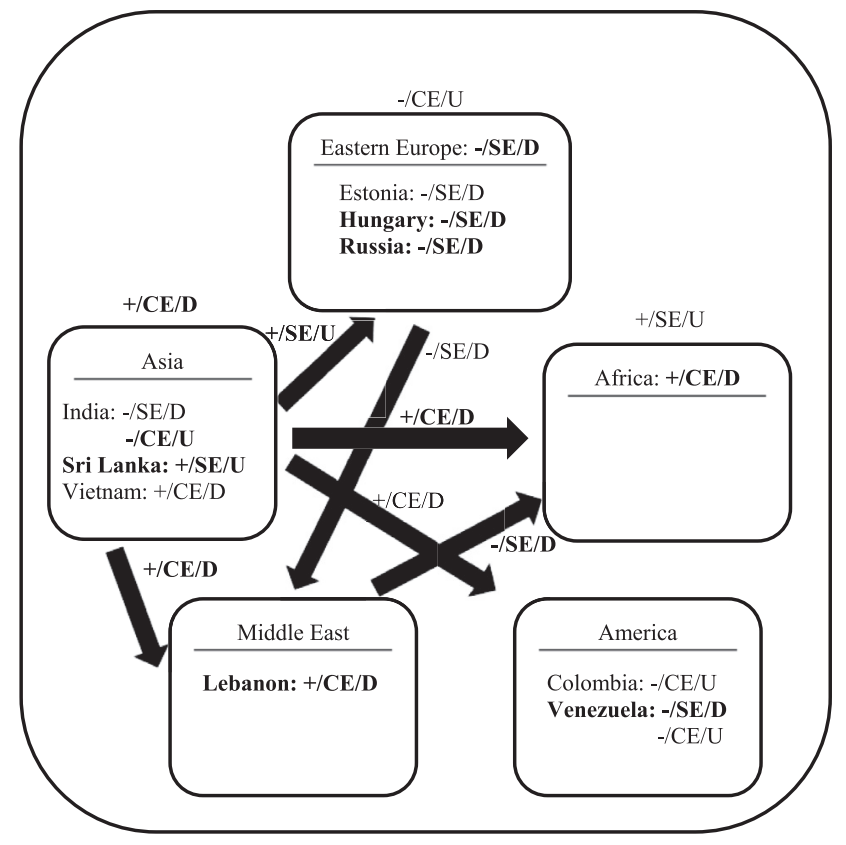

Fig. 5. Cross-border effects: rating changes versus outlooks and watch-lists.

This figure shows the results of the event study analysis for two different samples of rating events, considering the events, rating changes (Panel A), and outlooks and watch-lists (Panel B). It presents the different cross-border effects at the portfolio level and across all the countries and rating events found, differentiating the events into upgrades or downgrades. CE (SE) means the competition (spillover)

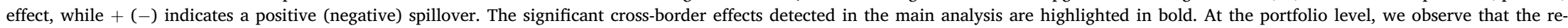

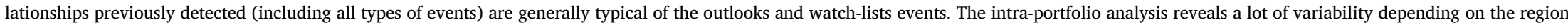
considered. There are some countries previously identified as transmitters that no longer appear in either of the two groups. Some other countries lead cross-border effects for the first time, indicating new

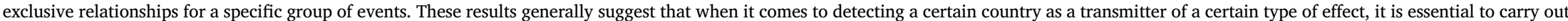
the analysis separately for each region. These effects are tested using the significance level employing the usual $t$-test, at the $10 \%(*), 5 \%(* *)$ or $1 \%$ level $(* * *)$. 
On average, the exclusion of these countries from the analysis does not lead to major differences. In fact, although they are relevant countries at the regional level (since all, except Brazil, show a significant impact on the main analysis), they are not the countries leading the transmission across regions (at least, not exclusively). The main relationships between portfolios that we found with the full sample of the 45 countries are still maintained when we exclude the BRICs from the sample. Asia once again stands out in its role as a transmitter of positive cross-border effects associated with downgrades. Additionally, a more in-depth analysis of the results reveals that the positive spillover effect due to upgrades that disappears with Asia as a transmitter to Eastern Europe may be linked to India, and more specifically to speculative-events, since this effect was characteristic of this type of event. ${ }^{19}$ On the other hand, the intra-portfolio analysis also shows very consistent results. The countries that exhibited a transmitter role across countries within the region remain. This implies that the BRICs are not the only countries reacting to these effects. The impact is much more general and affects the entire region as a whole. In summary, although initially we could assume that the BRICs may play a major role in cross-border transmission, in their position as stronger and more developed countries among the emerging economies, the findings clearly indicate otherwise.

\subsection{Post-event window}

We reproduce the event study analysis within a $[0,1]$ window. ${ }^{20}$ Overall, we do not observe relevant differences with respect to the analysis performed for the $[-1,1]$ window. Asia continues to play a key role as a transmitter to the rest of the portfolios, which are positively affected by downgrades in Asia. The only exception is America, which remains isolated from other regions. The intra-portfolio analysis shows the same type of effect as in the case of the $[-1,1]$ window for each of the portfolios on average across all the countries located in the same portfolio. The main differences lie in which countries result in significant effects within the portfolios. Although several countries maintain the same cross-border effects, more than a few countries are added to the list and others drop off. This indicates that in the case of some countries, the rating announcement in another country has been anticipated by the CDS market (those that no longer show effects in the $[0,1]$ window), while in others a delayed market reaction is observed (those that show new significant effects).

\section{Conclusions}

This work examines the spillover effects of sovereign credit rating announcements on sovereign CDS spreads by analysing a broad sample of developing countries over a twelve-year span (2004-2015). As expected, the quantity of evidence supporting the existence of cross-border impacts indicates that the effect of sovereign rating announcements should not be studied exclusively for the re-rated country, as the traditional literature has done, but also for the non-event countries.

The distinction in the analyses between the portfolio and intra-portfolio levels uncovers variations in the response of the CDS market across regions and rating locations. Although we observe some negative spillovers in response to downgrades, it is not the predominant effect, even in the crisis period. While this finding goes against the common result found in the literature, it is important to emphasise that the most related papers have focused mainly on the analysis of the bond market and exclusively on cross-country analysis. Consequently, the results suggest that cross-border effects should be analysed at an international or regional framework and not be generalised.

In fact, in terms of emerging portfolios, we only observe a negative spillover effect across regions, from Middle East to Africa. Moreover, the competitive effect (in which the role played by Asia stands out) is dominant over the spillover effect. The negative events in Asia, far from damaging other non-event regions, benefit the sovereign credit risk of Middle East and Africa. This indicates a competition effect associated with downgrades, since they entail better financing conditions in these particular surrounding emerging regions. On the other hand, the intra-portfolio analysis reveals different conclusions depending on the specific region. While most intraportfolio effects are due to upgrades in Asia and America, the effects associated with downgrades predominate in Eastern Europe, Africa and Middle East. More specifically, in the case of positive effects, upgrades (downgrades) in Bulgaria, Kazakhstan, Sri Lanka, Mexico and Panama (Slovenia, Lebanon and Egypt) improve the sovereign credit risk of neighbouring countries located in the same geographical area.

However, we should not play down the negative cross-border effects identified. At the portfolio level, only Africa suffers from upgrades (downgrades) in Asia (Middle East), although if we focus on the non-crisis period, Asia, Africa and Middle East are also harmed by downgrades in Eastern Europe. On the other hand, the intra-portfolio analysis reveals that upgrades (downgrades) in China, India and Chile (Hungary, Russia, Bahrain and Venezuela) should be closely monitored since they lead to a negative reaction in non-event countries that belong to the same region. The analysis by sub-periods reveals that, except for the case of Russia, these negative effects are all characteristic of the crisis period (in which Indonesia also shows a negative spillover effect due to downgrades).

The aforementioned emerging economies are the sources of financial instability, especially when the ratings are downgraded. Thus, we could expect that international investors are likely to withdraw funds not only from the downgraded country but also from the surrounding markets in the region, which contributes to increasing the regional negative transmission. In addition, this effect will be even more pronounced in times of crisis, as rating agencies are more prone to issue negative rating announcements.

The conclusions of this work could be applied in the real world. After analysing their investment portfolios, investors would be able to hedge against the risk of sovereign credit events in one economy affecting neighbouring countries not targeted by the rating event.

${ }^{19}$ China (the other BRIC country within Asia) is discarded because it does not exhibit upgrades in the speculative-events group.
${ }^{20}$ We do not report these results to save space. However, interested readers may obtain them from the corresponding author upon request. 


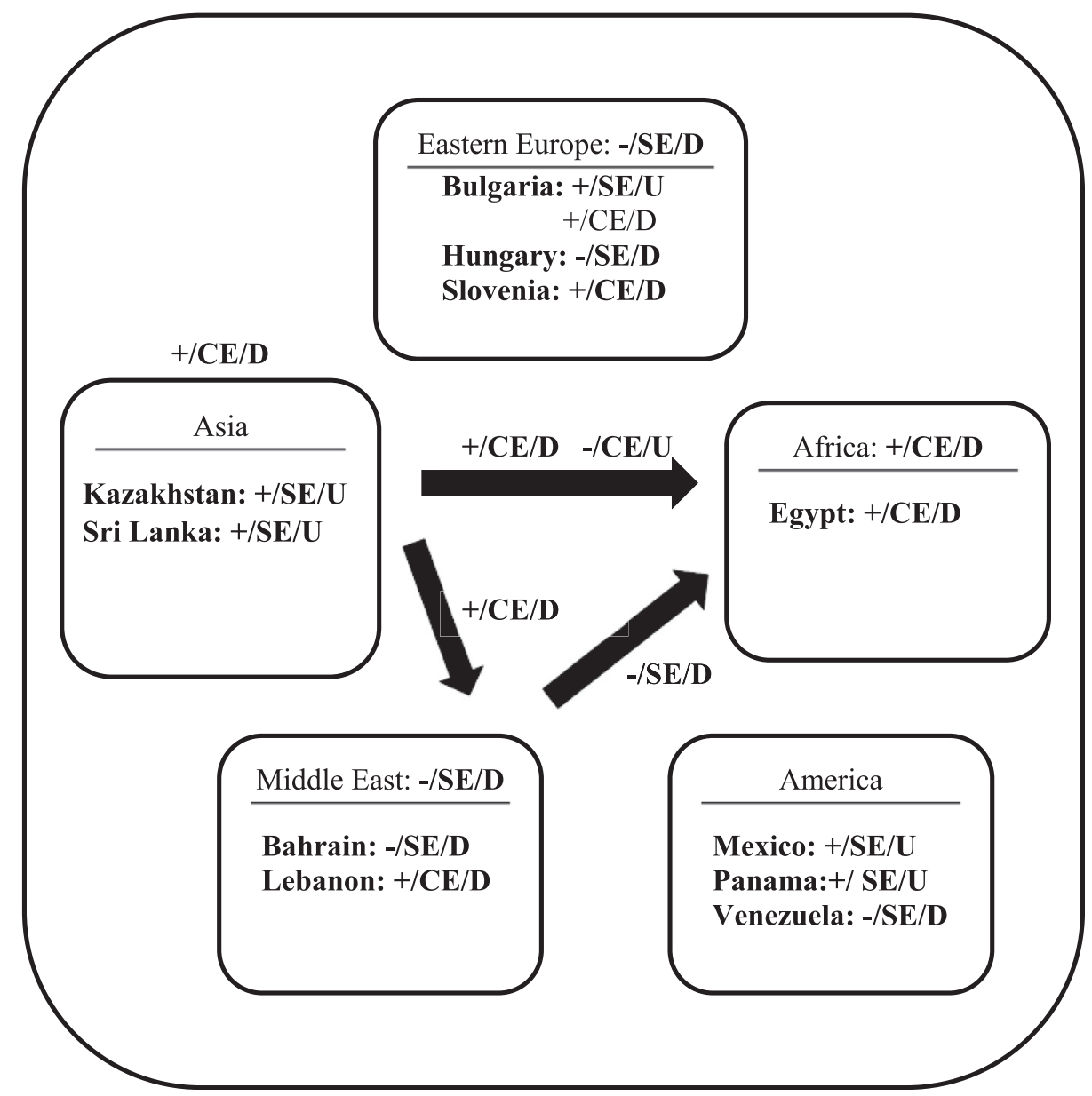

Fig. 6. Cross-border effects: excluding BRICs.

This figure shows the results of the event study analysis excluding BRIC countries (Brazil, Russia, India and China). It presents the different crossborder effects at the portfolio level and across all the countries and rating events found, differentiating the events into upgrades or downgrades. CE (SE) means the competition (spillover) effect, while $+(-)$ indicates a positive (negative) spillover. The significant cross-border effects detected in the main analysis are highlighted in bold. At the portfolio level, Asia once again stands out in its role as a transmitter of positive cross-border effects associated with downgrades. Additionally, a more in-depth analysis of the results reveals that the positive spillover effect due to upgrades that disappears with Asia as a transmitter to Eastern Europe may be linked to India, and more specifically to speculative-events, since this effect was characteristic of this type of event. The intra-portfolio analysis also shows very consistent results. The countries that exhibited a transmitter role across countries within the region remain. This implies that the BRICs are not the only countries reacting to these effects. These effects are tested using the significance level employing the usual $t$-test, at the $10 \%(*), 5 \%(* *)$ or $1 \%$ level $(* * *)$.

Information of this sort is vital for investors wishing to construct portfolios that are resilient against the effects of sovereign rating events. Furthermore, these findings allow the asymmetric effect created by credit rating announcements, whether positive or negative, to be identified. Additionally, given the significance and the expansion of the CDS market, seen as an acceptable indicator of the risk of default, decision makers should find these conclusions useful when revising capital requirement rules for specific economies and portfolios in the sovereign CDS market. Future research should consider analysing the potential determinants of the cross-market connectedness that we have found, in order to identify the drivers of the different existing transmission channels and, ultimately, to understand why investors see particular emerging economies as non-substitute or substitute assets.

\section{CRediT authorship contribution statement}

Laura Ballester: Investigation, Data curation, Writing - original draft, Writing - review \& editing, Visualization. Ana GonzálezUrteaga: Conceptualization, Methodology, Software, Writing - review \& editing, Project administration, Funding acquisition.

\section{Acknowledgement}

The authors acknowledge financial support from the Fundación Ramón Areces and from the Spanish Ministry of Science, Innovation 
and Universities and FEDER project PGC 2018-095072-B-I00. In addition, Laura Ballester acknowledges financial support from the Spanish Ministry of Science, Innovation and Universities and FEDER project PGC 2018-093645-B-I00 and Ana González-Urteaga acknowledges financial support from the Ministry of Economics and Competitiveness through grant ECO 2016-77631-R (AEI/FEDER.UE) and from the Ministry of Science and Innovation through grant PID 2019-104304 GB-I00/AEI/10.13039/501100011033. We would like to thank Lidia Sanchís, Alfonso Novales, Rafael Santamaria and M. Dolores Robles for valuable comments and discussions on earlier drafts of this paper. We also thank the participants at the XIII Workshop in Banking and Quantitative Finance, the Mathematical and Statistical Methods for Actuarial Sciences and Finance Conference (MAF), the Research Workshop on Credit Default Swaps, the Infiniti Conference on International Finance and the two anonymous referees for stimulating discussions.

\section{Appendix A. Supplementary data}

Supplementary data to this article can be found online at https://doi.org/10.1016/j.iref.2020.12.014.

\section{References}

Abad, P., Alsakka, R., \& Gwilym, O. (2018). The influence of rating levels and rating convergence on the spillover effects of sovereign credit actions. Journal of International Money and Finance, 85, 40-57.

Afonso, A., Furceri, D., \& Gomes, P. (2012). Sovereign credit ratings and financial markets linkages: Application to European data. Journal of International Money and Finance, 31(3), 606-638.

Ballester, L., Casu, B., \& González-Urteaga, A. (2016). Bank fragility and contagion: Evidence from the CDS market. Journal of Empirical Finance, 38, 394-416.

Ballester, L., \& González-Urteaga, A. (2017). How credit ratings affect sovereign credit risk: Cross-border evidence in Latin American emerging markets. Emerging Markets Review, 30, 200-214.

Baum, C. F., Schäfer, D., \& Stephan, A. (2016). Credit rating agency downgrades and the Eurozone sovereign debt crises. Journal of Financial Stability, $24,117-131$.

Blanco, R., Brennan, S., \& Marsh, I. (2005). An empirical analysis of the dynamic relation between investment-grade bonds and credit default swaps? The Journal of Finance, 60(5), 2255-2281.

Boehmer, E., Masumeci, J., \& Poulsen, A. B. (1991). Event-study methodology under conditions of event-induced variance. Journal of Financial Economics, 30(2), $253-272$.

Böninghausen, B., \& Zabel, M. (2015). Credit ratings and cross-border bond market spillovers. Journal of International Money and Finance, 53, $115-136$.

Candelon, B., Sy, M. A. N., \& Arezki, M. R. (2011). Sovereign rating news and financial markets spillovers: Evidence from the European debt crisis (No. 11-68). International Monetary Fund.

Chang, J. H., Hung, M. W., \& Tsai, F. T. (2015). Credit contagion and competitive effects of bond rating downgrades along the supply chain. Finance Research Letters, 15, $232-238$.

Christopher, R., Kim, S. J., \& Wu, E. (2012). Do sovereign credit ratings influence regional stock and bond market interdependencies in emerging countries? Journal of International Financial Markets, Institutions and Money, 22(4), 1070-1089.

De Santis, R. A. (2012). The euro area sovereign debt crisis: Safe haven, credit rating agencies and the spread of the fever from Greece, Ireland and Portugal. European Central Bank. working paper series 1419.

Drago, D., \& Gallo, R. (2016). The impact and the spillover effect of a sovereign rating announcement on the euro area CDS market. Journal of International Money and Finance, 67, 264-286.

Eichengreen, B., Mody, A., Nedeljkovic, M., \& Sarno, L. (2012). How the subprime crisis went global: Evidence from bank credit default swap spreads. Journal of International Money and Finance, 31(5), 1299-1318.

Ferreira, M. A., \& Gama, P. M. (2007). Does sovereign debt ratings news spill over to international stock markets? Journal of Banking \& Finance, 31(10), 3162-3182. Ferri, G., Liu, L., \& Stiglitz, J. E. (1999). The procyclical role of rating agencies: Evidence from the east Asian crisis. Economic Notes, $28,335-355$.

Finnerty, J. D., Miller, C. D., \& Chen, R. R. (2013). The impact of credit rating announcements on credit default swap spreads. Journal of Banking \& Finance, 37(6), 2011-2030.

Galil, K., \& Soffer, G. (2011). Good news, bad news and rating announcements: An empirical investigation. Journal of Banking \& Finance, 35(11), 3101-3119.

Gande, A., \& Parsley, D. C. (2005). News spillovers in the sovereign debt market. Journal of Financial Economics, 75(3), 691-734.

Hill, P., Brooks, R., \& Faff, R. (2010). Variations in sovereign credit quality assessments across rating agencies. Journal of Banking \& Finance, 34(6), 1327-1343.

Hull, J., Predescu, M., \& White, A. (2004). The relationship between credit default swap spreads, bond yields, and credit rating announcements. Journal of Banking \& Finance, 28(11), 2789-2811.

Ismailescu, I., \& Kazemi, H. (2010). The reaction of emerging market credit default swap spreads to sovereign credit rating changes. Journal of Banking \& Finance, 34(12), 2861-2873.

Jorion, P., \& Zhang, G. (2007). Good and bad credit contagion: Evidence from credit default swaps. Journal of Financial Economics, 84(3), 860-883.

Jorion, P., \& Zhang, G. (2010). Information transfer effects of bond rating downgrades. Financial Review, 45(3), 683-706.

Kaminsky, G., \& Schmukler, S. L. (2002). Emerging market instability: Do sovereign ratings affect country risk and stock returns? The World Bank Economic Review, 16(2), 171-195.

Kothari, S. P., \& Warner, J. B. (1997). Measuring long-horizon security price performance. Journal of Financial Economics, 43(3), $301-339$.

Longstaff, P. F., Longstaff, F. A., Mithal, S., \& Neis, E. (2003). The credit-default swap market: Is credit protection priced correctly? Working paper.

Longstaff, F. A., Pan, J., Pedersen, L. H., \& Singleton, K. J. (2008). How sovereign is sovereign credit risk? Working paper. UCLA and Stanford.

Mayordomo, S., Peña, J. I., \& Schwartz, E. S. (2014). Are all credit default swap databases equal? European Financial Management, 20 (4), 677-713.

Norden, L., \& Weber, M. (2004). Informational efficiency of credit default swap and stock markets: The impact of credit rating announcements. Journal of Banking \& Finance, 28(11), 2813-2843.

Reisen, H., \& Von Maltzan, J. (1999). Boom and bust and sovereign ratings. International Finance, 2(2), $273-293$.

Remolona, E., \& Scatigna, M. W. E. (2008). The dynamic pricing of sovereign risk in emerging markets. Journal of Fixed Income, 57-71.

Steiner, M., \& Heinke, V. G. (2001). Event study concerning international bond price effects of credit rating actions. International Journal of Finance \& Economics, 6(2), 139-157.

Wengner, A., Burghof, H. P., \& Schneider, J. (2015). The impact of credit rating announcements on corporate CDS markets-Are intra-industry effects observable? Journal of Economics and Business, 78, 79-91.

Williams, G., Alsakka, R., \& Gwilym, O. (2015). Does sovereign creditworthiness affect bank valuations in emerging markets? Journal of International Financial Markets, Institutions and Money, 36, 113-129.

Zhu, H. (2006). An empirical comparison of credit spreads between the bond market and the credit default swap market. Journal of Financial Services Research, 29(3), 211-235. 